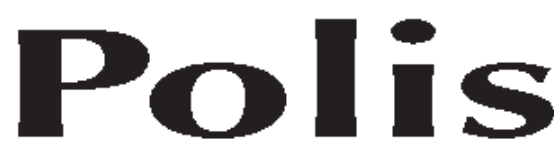

\title{
Otra verdad inconveniente: la nueva geografía política de la energía en una perspectiva subalterna*
}

\author{
Carlos Walter Porto-Gonçalves**
}

Para que las cosas permanezcan iguales, es preciso que todo cambie

(El leopardo, Lampedusa).

Resumen: El artículo busca explicar las razones de la conversión al discurso de la sustentabilidad, por parte del sector de los grandes productores de petróleo y el de los latifundios empresariales de monocultivos, que hegemonizan el agro negocio. Para ello, se analiza la forma como históricamente se ha constituido el bloque de poder hegemónico conformado como un complejo de poder técnico-científico-industrial-financiero-militar-mediático, del cual también participan los dueños de los agronegocios -el viejo bloque de poder modernizado. Se concluye que se avecina una verdadera tragedia con la expropiación generalizada que advendrá de la expansión del monocultivo latifundista modernocolonial de los agro negociantes que quieren someter la producción agrícola a la producción de combustibles de biomasa. Se señala la enorme importancia de comprender adecuadamente el carácter mundial del capitalismo y del papel del desarrollo de las fuerzas productivas que el capital impone al mundo y la necesidad de ejercer el derecho a la diferencia anclada en la defensa del territorio.

Palabras clave: bloque de poder, agrocombustibles, agronegocios, tropicalidad

\section{Another inconvenient truth: the new political geography of energy in a subordinate perspective}

Abstract: The article explains the reasons for the conversion to the speech of sustainability, on the part of large producers of petroleum and of large farms entrepreneurs of monoculture, who hegemonize the farming business. For that, the way in which this hegemonic sector -organized as a technical-cientific-industrial-financial-military-mediatic power, in which the owners of agrobusiness also participate, the old hegemonic power now modernized- has historically been reconstituted, is here analyzed. The conclusion is that a true tragedy is ahead, with the generalized expropriation that will occur by the expansion of modern-colonial large estate owner of the farming businessmen monoculture, who want to

\footnotetext{
* Texto presentado para debate en la reunión del Grupo de Trabajo Hegemonías y Emancipaciones, del Consejo Latino-Americano de Ciencias Sociales (CLACSO), en Guadalajara, México, entre el 12 y el 16 de agosto de 2007. Traducción de Antonio Elizalde.

${ }^{* *}$ Universidad Federal Fluminense, Niteroi, Brasil. Email: cwpg@ uol.com.br
} 
submit agricultural production to the biomass fuels production. The enormous importance of understanding the world scope of capitalism and the role of productive forces that the capital imposes, and the need to exercise the right to a different orientation anchored in the defense of territory, is hereby stated.

Key words: power block, agrocombustibles, agrobusiness, tropicality

En 2007 el calentamiento global apareció en los mass media no sólo impulsado por los ambientalistas, que venían pautando la cuestión en los últimos cuarenta años. Hollywood, inclusive, se rindió a esa "verdad inconveniente" laureando con el Oscar el documental del ex-vicepresidente de los Estados Unidos, Al Gore. Aún un analista como Ignacy Sachs llegó a afirmar, en la apertura de un seminario en el Instituto de Altos Estudios de la Universidad de São Paulo (USP), que el aumento de los precios del petróleo había hecho por el calentamiento global lo que los ambientalistas no habían conseguido hacer en los últimos treinta años. Esos dos hechos son buenas pistas para ayudar a entender lo que verdaderamente está en curso: la apropiación de una causa -el calentamiento globalpor sectores que hasta ahora se caracterizaron por descalificar a todos los que denunciaban el problema. Entre los recién conversos a la causa del calentamiento global están -nada más y nada menos- el sector de los grandes productores de petróleo y el de los latifundios empresariales de monocultivos que hegemonizan el mundo del agro negocio. ¿Qué los ha llevado a ese cambio de posición?

Los Estados Unidos ejercieron su hegemonía en el planeta por medio del dominio de las fuentes de energía fósil, base de todo el complejo sistema tecnológico industrial que tiene su núcleo en el uso generalizado de los motores Otto y Diesel. Primer país del mundo en explotar comercialmente el petróleo, en 1859, detuvo, en alianza con otras potencias imperialistas o contra ellas, en esos casos por el poderío militar, el control de áreas estratégicas de yacimientos de petróleo y carbón, lo que le proporcionó una posición relativamente confortable. ${ }^{1}$ La hegemonía estadounidense, sobre todo después de la Segunda Guerra Mundial, consiguió mantener el petróleo barato al menos hasta los años 1970, cuando se dio la primera crisis del producto, impulsada en gran medida por la onda de nacionalismos de variados matices que cubrió África, Asia, América Latina y el Oriente Medio. $^{2}$

\footnotetext{
${ }^{1}$ El carácter relativo de esa posición siempre estuvo en el horizonte de los estrategas estadounidenses. Es lo que se puede leer en el informe de 1928, en el cual se registra que los Estados Unidos son responsables "por casi tres cuartos de la producción mundial de petróleo", pero que, "a pesar de esa gigantesca producción, desde 1914 el enorme consumo (80,1\% de los automóviles del mundo) no puede ser abastecido por la producción de las fuentes propias" (Pahl, 1928, ap. Altvater, 1995, p.96).

${ }^{2}$ Sobre el nacionalismo, Noam Chomsky tuvo el mérito de alertar sobre ese hecho fundamental, a fin de entender el nuevo período que a partir de entonces se inicia, cuando el desmonte del Estado se torna una verdadera obsesión. Las luchas de liberación nacional, durante la Guerra Fría, a las que estuvieron vinculados muchos movimientos de izquierda, hizo que ellas fuesen interpretadas como confrontaciones entre el capitalismo y el socialismo. Mientras tanto, la crisis del socialismo a fines de los años 1980 sólo vendría a confirmar, por la continua política de desmonte del Estado-nación y de cualquiera veleidad nacionalista, que la desconstrucción del Estado nacional es el soporte de las políticas neoliberales que nacieron con la crisis del petróleo y tuvieron su primera sistematización en Chile, con el advenimiento de los Chicago Boys en 1976.
} 
A partir de ese contexto, entra en curso una revolución en las relaciones sociales y de poder por medio de la tecnología (Porto-Gonçalves, 2006), en que cada vez se hablará más de nuevos materiales, de economía de uso de los recursos naturales, sobre todo de los norenovables. Grandes corporaciones (IBM, Remington-Rand, Fiat, Xerox, Ollivetti, entre otras) en su época llegaron a patrocinar el importante informe Los límites del crecimiento, también conocido como Informe Meadows del Massachusetts Institute of Technology (MIT), en el cual, por primera vez, se habló abiertamente de los límites de los recursos naturales para el crecimiento económico (id., 1983). Ya allí, un ecologismo empresarial comienza a disputar espacio con el movimiento ambientalista.

La historia de los últimos treinta a cuarenta años confirmó que el capitalismo sin crecimiento económico es una contradicción en los términos, y que, por más que las políticas de racionalización de energía y uso de los recursos naturales hayan obtenido algún éxito, la demanda por recursos naturales continúa aumentando exponencialmente. ${ }^{3}$ Vivimos la paradoja de ver la constitución del campo ambiental conviviendo con los treinta/cuarenta años en que más se devastó el planeta, aún con toda la high technology que nos ha sido ofrecida à la carte (id., 2006).

A partir de la década de 1970, algunos países, como Brasil, avanzaron tecnológicamente en la búsqueda de fuentes renovables de energía. Sin embargo, la conditio sine qua non capitalista, con su lógica determinada por las tasas de lucro (y cada vez más por las tasas de intereses), se impuso como el mayor obstáculo para que una verdadera transición de la matriz energética se generalizara (retomaremos el argumento más adelante). La derrota impuesta a los proyectos socialistas y nacionalistas mantuvo el petróleo barato hasta fines de los años $1990,{ }^{4}$ lo que hizo económicamente inviables, aunque necesarias, las alternativas energéticas. Considérese que, cuando los precios del petróleo estaban en torno a US\$25 el barril, como antes de la segunda guerra contra Irak, se evaluaba que el coste militar para garantizar ese abastecimiento equivalía a US\$ 75 por barril. El 11 de Septiembre de 2001 exacerbó ese contexto geopolítico y expuso los límites

\footnotetext{
${ }^{3}$ Aumento este que no se da por el crecimiento demográfico, sino sobretodo por la "fabricación capitalista de la subjetividad" (Félix Guattari). El historiador inglés E. Thompson (1996) afirmó que la generación postaños 1960 es la primera em la historia de la humanidad en que los grupos de socialización primaria, como la familia y la comunidad inmediata de vecinos, perdieron el poder de conformar las necesidades de sus propios hijos en favor de las "máquinas de fabricación de la subjetividad" que son los medios de comunicación.

${ }^{4}$ Aunque con la obligación de una intervención militar en Iraq, en 1991.
} 
del complejo corporativo técnico-científico-industrial-militar-mediático que tiene como esencia el control de los combustibles fósiles. ${ }^{5}$

Los eventos que se sucedieron al huracán Katrina, en 2005, contribuyeron no sólo a develar el descompromiso de la política estadounidense con el calentamiento global, como a debilitar el bloque de poder que domina los Estados Unidos con fuertes raíces en el sector de los combustibles fósiles y el militar, cosechando así los malos frutos de su segunda intervención militar contra Irak.

Todo indica que la derrota, sobre todo política, de la intervención militar en Irak y en Afganistán, ha cumplido un papel relevante en el cambio de posición política, inclusive por sus implicaciones en la derrota electoral, en 2006, de los republicanos en las elecciones para el Congreso de los Estados Unidos. Esa derrota política tiene implicancias incluso para el mantenimiento de los actuales contingentes militares en las plazas de guerra, en la medida en que los elevados precios del petróleo, causados en gran medida por la propia intervención militar, crearon una brutal desproporción presupuestaria de difícil negociación en un Congreso de mayoría demócrata. Añádase, además, la derrota del proyecto del Área de Libre Comercio de las Américas (ALCA) y las movilizaciones en torno a la reapropiación de los recursos naturales y contra las políticas neoliberales en América Latina, sobre todo después de la victoria electoral de candidatos que, de manera más o menos intensa, le dieron curso a esas movilizaciones, ${ }^{6}$ como Hugo Chávez en Venezuela (1998), Néstor Kirchner en Argentina (2002), Evo Morales en Bolivia (2005) y Rafael Correa en el Ecuador (2006).

Tal como en los años 1970, cuando los límites naturales fueron invocados como "límites del crecimiento" por el Club de Roma, nuevamente se recurre a la naturaleza para justificar políticas en el mejor estilo de El leopardo, de Lampedusa, con su tesis de que, "para que las cosas permanezcan iguales, es preciso que todo cambie". Así, el calentamiento global viene ganando un nuevo sentido, no más por las razones que el movimiento ecologista había reivindicado, sino por los valores y principios estratégicos de los recién-convertidos de mantenerse en el centro de las relaciones de

\footnotetext{
${ }^{5}$ Además, por mayor que sea el desarrollo tecnológico y científico, la transformación de la materia depende de la energía cuya materia no es producida por el desarrollo científico y tecnológico, sino que por la naturaleza. Si hubiese la posibilidad de producir esa materia en los propios países centrales gracias a su poderío científico y tecnológico, la dimensión geopolítica derivada de la dependencia de recursos naturales desaparecería. Considérese que los Estados Unidos mantienen 727 bases militares fuera de su territorio, con un contingente de aproximadamente 300 mil militares.

${ }^{6}$ Por motivos que se tornan fáciles de entender, la política de Luiz Inácio Lula da Silva, electo en 2002, va a mostrarse más ambigua, aunque manteniendo cercanía con esos gobiernos.
} 
poder. ${ }^{7}$ A juzgar por la pujanza de esos protagonistas en el cuadro de las relaciones sociales y de poder del capitalismo contemporáneo, son enormes las implicaciones de ese cambio político. Antes que nada, es preciso tener en cuenta que estamos delante de un debate en torno a la matriz energética, particularmente de cambios en las fuentes de energía. Y la energía, no es una materia cualquiera, sino una a partir de la cual se transforman otras materias. La energía es la capacidad de realizar trabajo, y trabajo es la capacidad de transformar la materia, como lo enseñan los físicos. ${ }^{8}$ Las implicaciones de eso son enormes, en la medida en que son, al mismo tiempo, políticas y epistémicas. Hasta aquí, el fundamento filosófico antropocéntrico de tradición europea ha acentuado, tanto en la derecha y como en la izquierda, el papel redentor de la tecnología; como si el sistema técnico operara en un vacío material y afuera de las relaciones sociales y de poder. La desconsideración de la dimensión energético-material de la dinámica económica, que caracteriza el mainstream de la economía, se manifiesta, hoy, en el propio calentamiento global, como lo enseñan las leyes de la termodinámica (entropía). La reducción de la economía a lo que Aristóteles llamó "crematística", es decir, a las relaciones de precios, hizo con que se subsumiese el material a lo simbólico, a lo cifrado y, así, se confundieran las cosas de la lógica con la lógica de las cosas. El efecto invernadero es el resultado del éxito de la matriz energética de la revolución (en las relaciones sociales y de poder) industrial, saludada en prosa y verso como la afirmación del proyecto civilizatorio eurocéntrico que prometía emancipar la humanidad de la naturaleza con la máquina a vapor. La cuestión remite a los límites que esa misma matriz epistémica y política ofrece. Como los paradigmas no son instituciones que se caen del cielo -sino, al contrario, son instituidos por sujetos de carne y hueso en el terreno de las luchas sociales-, es sobre esto que este artículo trata: de las luchas en curso en el ámbito de las relaciones sociales y de poder contemporáneas por medio de la tecnología de la energía. Está siendo engendrada

\footnotetext{
${ }^{7}$ No discutiré aquí las limitaciones de la energía de la biomasa para mitigar el calentamiento global. Además de la idea, simplista, de que pueda haber una solución única para un problema de tal magnitud y complejidad, han sido varios los análisis que apuntan hacia lo delirante de esa tesis, entre otras por la imposibilidad de disponer de tierras suficientes para alcanzar la demanda de energía, que continua creciendo. Ese es un problema que sobrepasa con creces a los que están más preocupados de aprovechar la oportunidad para hacer buenos negocios con la creciente demanda de energía que en resolver el problema del calentamiento global.

${ }^{8}$ El destacado papel de Al Gore en esta nueva alerta sobre el calentamiento global es emblemático sobre lo que está en curso. Finalmente, la energía es, en los Estados Unidos, como debería ser en cualquier país del mundo, una cuestión de Estado y no del gobierno de turno, y en la conformación de los bloques de poder el sector energético cumple, por eso mismo, un papel central. Esa es la razón por la que Al Gore, habiendo él mismo ocupado la Casa Blanca junto con Bill Clinton, no firmó el Protocolo de Kyoto. Las propuestas que el gobierno de Clinton y Gore llevaban a las reuniones internacionales que debatían el asunto eran, simplemente, inaceptables para los demás países y por todos aquellos interesados en encontrar una solución, puesto que provenían del complejo técnico-científico-industrial-militar-financiero-mediático ligado a la matriz energética fosilista.
} 
una nueva geografía política, y buscaremos aquí desvelarla a la luz de las enseñanzas de los grupos subalternos.

\section{La nueva configuración de un viejo bloque de poder}

Son graves las implicaciones de la tesis, repetida ad nauseam, según la cual las transformaciones sociales, políticas y culturales en el mundo durante las últimas tres décadas son el efecto de las transformaciones tecnológicas (comunicación, informática, nanotecnología, nuevos materiales, biotecnología, óptica), sin preguntarse quién pone en movimiento la revolución tecnológica en marcha (Porto-Gonçalves, 2006). O sea, la revolución tecnológica no se pone en movimiento por sí misma -he ahí los límites de ese fetichismo de la tecnología que ve relaciones entre cosas, donde hay relaciones entre grupos, personas y clases sociales. Finalmente, lo que está en curso no es solamente una nueva matriz energética o una "transición energética", sino un reacomodo en las relaciones sociales y de poder por intermedio de la tecnología. El análisis para entender la coyuntura debe partir de la identificación de quien protagoniza esa "transición energética". En 2006, fue constituida la Asociación Interamericana de Etanol (AIE), teniendo como sus dos principales dirigentes a Roberto Rodrigues, entonces ministro de la Agricultura de Brasil, y a Jeb Bush, ex-gobernador de Florida y hermano del actual presidente de los Estados Unidos. ${ }^{9}$ Se trata de la conformación de una alianza política, ahora a escala global, de lo que ya venía siendo forjado en Brasil desde los años 1970 cuando, a partir de la crisis del petróleo, el gobierno dictatorial brasileño desencadenó un programa de gran envergadura de producción de combustible a partir de biomasa, el Pro alcohol. Ya en la época, los viejos productores latifundistas con sus monocultivos de caña de azúcar, en el poder hace cinco siglos en Brasil, se transformaron en los grandes héroes nacionales, porque ofrecían una alternativa de fuente energética a la crisis que se había instalado con el aumento de los precios del petróleo. ${ }^{10}$

Nuevamente estamos delante de una importante revolución tecnológica que surge en

\footnotetext{
${ }^{9}$ Roberto Rodrigues es agrónomo y uno de los principales articuladores de la Associação Brasileira de Agribusiness (Abag), entidad de la cual fué presidente hasta ocupar el Ministerio de Agricultura, convidado por el presidente Lula. Jeb Bush tiene notorias vinculaciones con el complejo corporativo técnico-científicoindustrial-militar-financiero-mediático, con fuertes lazos con el sector que controla los combustibles fósiles. 10 No es la primera vez que esa clase se presenta como la de los "grandes héroes nacionales". Desde los primeros ingenios de caña de azúcar introducidos en el Brasil, en 1532, las relaciones del Estado con el sector son íntimas, también porque las tierras (sesmarias) que recibían del Rey de Portugal sólo serían mantenidas si hacían efectiva la conquista territorial, objetivo mayor de la Corona portuguesa. $\mathrm{O}$ sea, el interés económico de los señores del ingenio se subordinó a los objetivos estratégicos de conquista territorial desde el período colonial. Desconsiderar estos hechos por una lectura economicista de la historia nos ha impedido entender los verdaderos móviles de la formación histórico-geográfica del territorio.
} 
la periferia del sistema-mundo; ${ }^{11}$ tal como la que se forjó a la época colonial y que fue capaz de afirmar todo un bloque de poder que hegemonizó el mundo hasta el siglo XVIII, esa nueva revolución tecnológica se ensaya como un reacomodo en las relaciones sociales y de poder por medio de la tecnología con el control de las nuevas fuentes de energía. No es otro el sentido de la AIE. En Brasil, el Pro alcohol selló una alianza estratégica entre industriales de azúcar, gestores estatales, centros de investigación e industria automovilística. Por último, en el tanque de gasolina se había conformado un acuerdo político entre dos grandes sectores de las clases dominantes que, por medio de la tecnociencia y de los gestores estatales, afirmaban su ideología moderna colonizadora de cinco siglos. Al final, somos modernos desde hace cinco siglos.

Las tecnociencias, como enseña Pablo González Casanova, adquieren un papel central en la reproducción del capitalismo bajo la hegemonía de los grandes complejos empresariales corporativos, sobre todo después de la Segunda Guerra Mundial. Por las dimensiones que el capitalismo viene adquiriendo en Brasil, la cuestión científica y tecnológica también asume una enorme centralidad. En los años 1970, cupo a los militares ${ }^{12}$ establecer un programa específico de investigación de otra fuente de energía, con el Pro alcohol, no por motivos ecológicos, pues al mismo tiempo invertían en un proyecto nuclear brasileño.

La centralidad que el Estado asumió en esa época fue sustituida, hoy, por una nueva reconfiguración del bloque de poder, en que los mayores beneficiarios empresariales del régimen dictatorial ganaron centralidad, subordinando a los gestores estatales. Es necesario

\footnotetext{
${ }^{11}$ Por sus implicaciones epistémicas y políticas, es importante registrar que, una vez más, transformaciones capaces de engendrar ciclos tecnológicos à la Kondratieff tienen orígen en la periferia del sistema-mundo, y no en sus centros hegemónicos. En el período colonial, la tecnología de mayor produtividad, los ingenios de azúcar, se desarrollaron em la periferia del sistema-mundo, primero em el archipélago de Cabo Verde y, después, en los ingenios de Brasil, Cuba y Haití. Finalmente, de aquí no se exportaba simplemente materia prima, como lo registran los libros de historia y de economía, sino un producto manufacturado, como el azúcar. La colonialidad del saber, como se vé, es parte de la colonialidad del poder, como un producto manufacturado, como el azúcar. La colonialidad del saber, como se ve, es parte de la colonialidad del poder, como lo enseñan Aníbal Quijano, Fernando Coronil, Arturo Escobar, Edgardo Lander, Walter Mignolo, Catherine Walsh, Silvia Rivera Cusicanqui y tant@s otr@s.

${ }^{12}$ El estamento militar, en Brasil, siempre consideró al desenvolvimiento científico y tecnológico uno de los triunfos fundamentales para el ejercicio del poder. Los militares protagonizaron la creación de la principal institución de investigación científica en Brasil, en 1951, el Consejo Nacional de Desenvolvimiento Científico y Tecnológico (CNPq). Se buscaba, con eso, el dominio de la energía atómica, según ellos la única manera de garantizar la soberanía nacional después de Hiroshima y Nagasaki. En 1954, los militares fueron uno de los protagonistas de la campaña "El petróleo es nuestro", que llevaría a la creación de Petrobras y al estabelecimiento del monopolio sobre la explotación del petróleo en Brasil. La inversión científica y tecnológica iniciada por el Estado llevaría a hacer de Petrobras una de las mayores empresas del mundo y pionera en la exploración de petróleo en aguas profundas.
} 
considerar que las dictaduras bajo el comando de los militares que cubrieron América Latina en las décadas de 1960-70 fueron una respuesta a la coyuntura revolucionaria que se siguió a la Revolución Cubana, cuando la cuestión agraria había ganado relevancia poniendo en jaque la estructura de poder basada en el latifundio. ${ }^{13}$ Las oligarquías latifundistas supieron moverse políticamente en esa reconfiguración, inclusive alejando cualquier perspectiva de democratización de la propiedad de la tierra, aún aquellas en que los Estados Unidos pusieron en práctica como contrapunto a la reforma agraria, de lo cual Japón y Puerto Rico son buenos ejemplos. Al contrario, las oligarquías latifundistas salieron fortalecidas, asociándose a aquellos que, temiendo la Revolución Roja que proponía transformar la estructura social, económica y política, impusieron la Revolución Verde, de carácter técnico-científico. Organismos multilaterales, como la Food and Agriculture Organization (FAO) y el Consultative Group on International Agricultural Research (CGIAR), en asociación con grupos empresariales, como Rockefeller, conformaron un complejo técnico-científico-industrial-financiero-mediático, involucrando Estados donde las clases dominantes se comprometieron en la lucha contra la reforma agraria en nombre del desarrollo contra cualquier perspectiva transformadora. A eso, los científicos políticos lo llamaron "modernización conservadora".

El sociólogo Pablo González Casanova, en Las nuevas ciencias y las humanidades: de la academia a la política, resalta la complejidad que el capitalismo adquiere en la posguerra -en el lugar de los grandes trusts y carteles, con sus monopolios especializados y sectorializados (Thyssen, Krupp, Ford etc.), pasa a haber grandes complejos corporativos técnico-científico-industrial-financiero-militar-mediáticos multidimensionales. ${ }^{14}$

Finalmente, un nuevo bloque de poder viene estructurándose entre nosotros, sobre todo desde los años 1960-70, y hoy busca sacar provecho de las propias contradicciones apuntadas críticamente por los movimientos sociales, como el movimiento ambientalista. Incorpora una retórica ambiental, buscando, así, prestar legitimidad a una nueva matriz energética por medio de la cual persigue mantener el poder. En presencia del pionerismo político y técnico de Brasil en la conformación de esa matriz energética, el análisis de la constitución de ese nuevo bloque de poder ayuda a entender el diseño técnico-político que se engendra, de lo cual la AIE es la mejor expresión, por sus implicaciones geopolíticas.

\footnotetext{
${ }^{13}$ En Brasil, por ejemplo, las Ligas Campesinas tuvieron un papel relevante antes del golpe de Estado de 1964

${ }^{14}$ A modo de ejemplo, llamo la atención hacia el cambio de paradigma - del cartesianismo para la teoría de la complejidad, la teoría del caos, la teoría de los fractales-, manteniéndose las relaciones sociales y de poder asimétricas, o más bien, aún más asimétricas. Así, aquellos que vean en la crisis del paradigma cartesiano la emergencia de una perspectiva emancipatoria y liberadora tendrían que revisar sus análisis. Las nuevas ciencias rompen con las dicotomías, como la que separa sujeto y objeto, y pasan a constituir una ciencia por objetivos, entre los cuales aparece el de reprimir cualquier perspectiva transformadora. Así, el cambio de paradigma bien puede ser a la Lampedusa.
} 
Así como aquello que vendría a ser conocido como políticas neoliberales fue siendo engendrado en el terreno movedizo de las luchas sociales, habiéndose iniciado con los Chicago Boys asesorando la dictadura de Pinochet en Chile a partir de 1976, ${ }^{15}$ algo similar puede ser observado en la conformación del nuevo bloque de poder, inspirado en lo que Pablo González Casanova llamó complejo de poder técnico-científico-industrial-financieromilitar-mediático. De la década de 1930 a la de 1960, en Brasil, las oligarquías latifundistas hicieron valer sus intereses político-económicos por intermedio de instituciones sectorializadas, como el Instituto del Azúcar y del Alcohol (IAA) y el Instituto Brasileño del Café (IBC). Un nuevo dibujo comienza a ganar contorno desde los años $1960 \mathrm{y}$, después de mucho ensayo y error, gana sistematicidad en los años 1990 con la creación de la ABAG. En torno a una noción libre y sin consistencia conceptual, como la del agro negocio, que engloba experiencias y formaciones socioculturales tan diversas ${ }^{16}$ que ningún científico social serio jamás osaría agruparlas bajo la misma rúbrica, se desarrolla una nueva forma de hacer política por parte de los grandes grupos empresariales -teniendo como fundamento la gran propiedad de la tierra concentrada y/o subordinando pequeños productores por la integración oligopsónica, aún aquí estimulando la concentración de la actividad con la eliminación de numerosas propiedades. ${ }^{17}$

La ABAG, actuando con otras instituciones, tiene un papel destacado en la conformación del nuevo bloque de poder. Los agrocombustibles son un lugar estratégico, pues en él se articula un poderoso bloque de poder con la alianza de grupos industriales, financieros, latifundistas, de intelectuales integrados y acríticos tanto en las universidades y centros de investigaciones como en los mass media -de ahí el complejo de poder técnicocientífico-industrial-financiero-militar-mediático. En la web de la ABAG (www.abag.con.br) hay, entre las 58 entidades a ella asociadas, las siguientes:

1) empresas y asociaciones del sector de industrias de alimentación, nutrición animal, fertilizantes, biotecnología y semillas: ADM de Brasil Ltda. (Archer Daniels Midland Company) | AGCO de Brasil | Agroceres Nutrición Animal Ltda. | Agropalma S.A. | Asociación Brasileña de la Patata (Abba) | Asociación Brasileña de Industrias de la

\footnotetext{
${ }^{15}$ Eso después de tres trágicos años en que la dictadura de Pinochet se encargó de destruir la experiencia socialista y democrática de Salvador Allende, mediante tortura y asesinatos.

${ }^{16}$ En un debate en una importante universidad brasileña, un estudioso, que llegaría a ser uno de los próceres de la creación de un curso de agro negocios, afirmó, sin la menor ceremonia, que agro negocio es toda práctica que envuelve la venta de productos de origem agropecuario. Como ejemplo, para mi espanto, dijo que un indígena, cuando vendía sus productos, hacía parte del agro negocio. La ideología no podría ir más lejos.

${ }^{17}$ En el oeste catarinense, en la región de Concórdia y Chapecó, entre 1980 y 2000 el número de establecimientos productores de cerdos y pollos diminuyó de $67 \mathrm{mil}$ a $20 \mathrm{mil}$, al mismo tiempo que su volumen de producción se triplicó.
} 
Alimentación (Abia) | Asociación Brasileña de los Criadores de Cebú (ABCZ) | Asociación de la Industria del Azúcar y Alcohol (Aiaa) | Asociación Nacional de Defensa Vegetal (Andef) | Bunge Alimentos S.A. | Bunge Fertilizantes S.A. | Caramuru Alimentos S.A. | Cargill Agrícola S.A. | Cocamar Cooperativa Agroindustrial | Compañía de Tejidos Norte de Minas (Coteminas) | Coopavel Cooperativa Agroindustrial | Cooperativa Agropecuaria de Araxá (Capal) | Cooperativa Agroindustrial de los Productores Rurales del Suroeste Goiano (Conmigo) | Cooperativa Regional de los Cafeicultores de Guaxupé Ltda. (Cooxupé) | Du Pont de Brasil S.A. | División Pioneer Semillas | Federación de las Cooperativas del Estado de Rio Grande do Sul (Fecoagro/Fecotrigo) | Goodyear de Brasil Productos de Goma Ltda. | Maeda S.A. - Agroindustrial | Malteria del Vale S.A. | Pirelli Neumáticos S.A. | Sadia S.A. | Sindicato Nacional de la Industria de Defensivos Agrícolas (Sindag) | Syngenta | Unión de la Industria de Caña-de-Azúcar (Unica) | Unión de los Productores de Bioenergia (Udop) | Fábrica Alto Alegre S.A. - Azúcar y Alcohol;

2) empresas del sector de consultoría: Ceres Consultoría S/C Ltda. | MRS Logística S.A. | Pricewaterhouse Coopers | Cosechas \& Mercado;

3) empresas del sector de periodismo y comunicaciones: Agencia Estado | Algar S.A. Iniciativas y Participaciones | Globo Comunicación y Participaciones S.A. | Trademaq Eventos y Publicaciones Ltda.;

4) empresas del sector financiero: Banco Cooperativo Sicredi S.A. (Bansicredi) | Banco de Brasil S.A. | Banco del Estado de São Paulo S.A. (Banespa) | Banco Itaú BBA S.A. | Bolsa de Mercancías y Futuros (BM\&F);

5) empresas del sector químico: Basf S.A. | Bayer S.A. | Du Pont de Brasil S.A. | Evonik Degussa Brasil Ltda. | FMC Química de Brasil Ltda. | Monsanto de Brasil Ltda.;

6) empresas del sector de máquinas y implementos: John Deere Brasil S.A. I Máquinas Agrícolas Jacto S.A. | CNH Latin America Ltda. - División Agrícola - Case CE | Marchesan Implementos y Máquinas Agrícolas Tatu S.A.;

7) empresas gigantes del sector de minero: Compañía Vale del Río Dulce | Petróleo Brasileño S.A. (Petrobras);

8) instituciones del sector de investigaciones, sobre todo estatales: Empresa Brasileña de Investigación Agropecuaria (Embrapa) | Fundación de Estudios Agrarios Luiz de Queiroz (Fealq).

Así, el complejo corporativo multidimensional de poder se hace evidente. Envuelve empresas de los sectores agrícola e industrial (de biotecnología, máquinas y equipamientos, química, de extracción mineral, inclusive de petróleo), financiero, de consultoría e instituciones de investigación científica y tecnológica, y de comunicaciones (radio, 
periódico y televisión).

Nótese, además, como ese bloque de poder se articula con alianzas supranacionales, envolviendo gigantes como Bunge, Syngenta, Monsanto, Saludable, Basf, John Deere, Bayer, Du Pont, Pirelli, Pricewaterhouse Coopers, Petrobras, Vale del Río Dulce, Goodyear y ADM. No son, por lo tanto, intereses nacionales los que comandan las acciones de ese bloque de poder, que sin embargo viene impulsando la política de los Estados por intermedio de esas organizaciones paragubernamentales que conforman las nuevas formas del hacer político. La Abag, junto con La Asociación Brasileña de los Productores y Exportadores de Pollos (Abef), la Asociación Brasileña de las Industrias Exportadoras de Carnes (Abiec) y la Unica, es miembro del consejo director del Instituto de Estudios del Comercio y Negociaciones Internacionales (Icone). Esta es una institución privada creada en 2003 "en respuesta a la necesidad de proveer al gobierno y al sector privado estudios e investigaciones aplicadas en temas de comercio y política comercial, relacionados principalmente al área de la agricultura y del agro negocio", cuya misión es "entender la dinámica global del agro negocio, de la bioenergía y del comercio exterior por medio de la investigación aplicada, contribuyendo, así, para profundizar la inserción económica de Brasil en el mundo". ${ }^{18}$ Como se percibe, cuatro entidades privadas conectadas a sectores altamente oligopolizados (carne, pollo, azúcar y alcohol), bajo la articulación de la Abag, hacen que sus intereses específicos conduzcan la política exterior de Brasil; inclusive, uno de sus principales ideólogos, Roberto Rodrigues, ex-director de la ABG, fue ministro de Agricultura, y Luiz Furlan, ex-director de Sadia, ocupó la cartera de Industria y Comercio en el gobierno de Lula.

En Brasil, fue montado un complejo sistema de investigación ${ }^{19}$ en torno a los agro combustibles, lo cual envuelve varias instituciones: la EMBRAPA, ${ }^{20}$ con sus cuatro programas (Biodiesel, "Bosques Energéticos" [sic], Etanol y Residuos); la Escuela Superior de Agricultura Luiz de Queiroz (Esalq), localizada en Piracicaba (SP); el Programa de Estudios de los Negocios del Sistema Agroindustrial (Pensa), "organización del tipo network que integra los Departamentos de Economía y Administración de la FEA-USP"; además del Icone -todos comprometidos en un gran proyecto estratégico de hacer del sector un protagonista global.

\footnotetext{
${ }^{18}$ Disponible en: 〈www.iconebrasil.org.br/pt>. Acceso: 25 de enero de 2008

${ }^{19}$ Ya en la época de la dictadura, fue creado un complejo de investigación técnico-científica. Según el físico Bautista Vidal, uno de los principales formuladores de Pro alcohol, el programa llegó a envolver, bajo su responsabilidad, 1.600 científicos trabajando de manera coordinada en todo el Brasil.

${ }^{20}$ La EMBRAPA se ha destacado, entre otros aspectos, por las pesquisas que proporcionaron la apertura de las amplias regiones de los planaltos centrales brasileños, con más de 300 millones de hectáreas de sabanas (cerrados), para la ocupación por ese complejo corporativo latifundista de monocultivos, sobretodo con la adaptación genética de plantas de regiones de clima templado a los climas tropicales, como la soja.
} 
La importancia del agro negocio como ideología puede ser notada por la asociación a la ABAG de, al menos, dos grandes grupos empresariales del sector de comunicaciones: la Agencia Estado, que edita uno de los periódicos más importantes de Brasil (El Estado de S. Paulo), y las Organizaciones Globo, el mayor grupo empresarial de comunicaciones del país. Sabiéndose que no hay consenso entre los científicos acerca de temas tan complejos como los efectos de la expansión de los monocultivos, de los organismos laboratorialmente modificados (OLMs), de la polución química y de la erosión genética, la población ha sido víctima de informaciones tendenciosas que ofrecen una certeza técnica y científica inexistente entre los propios científicos. Como la prensa precisa del mito de la neutralidad para legitimarse, hay que interrogarse sobre la veracidad de las informaciones acerca de la calidad de los alimentos y de los remedios, y sobre las implicaciones socio ambientales del modelo agrario-agrícola protagonizado por los agro negociantes, cuando se sabe que grandes empresas de comunicación están formalmente asociadas a ese complejo de poder, conforme se puede leer en la Web de la ABAG.

El ingeniero Evandro Mantovani, presidente de la Asociación Brasileña de Ingeniería Agrícola (SBEA) y jefe de la Secretaría de Gestión y Estrategia de la EMBRAPA, afirmó en un seminario realizado en la USP, en 2006, que la EMBRAPA mantenía centros de investigación en Estados Unidos, en Europa y en África. El físico Roberto Kishimani, exdirigente del Greenpeace en Brasil y hoy consultor de grandes corporaciones empresariales, nos informa de las gestiones de la USP con empresas y universidades de Estados Unidos para establecer una empresa joint venture de investigación, apuntando a patentar nuevos motores con fuentes alternativas de energía. En esos círculos, se habla abiertamente del carácter global de la nueva configuración de las relaciones sociales y de poder por medio de la tecnología. Al mismo tiempo que se habla de articulaciones de investigación científica con Estados Unidos y Europa, se viaja, a menudo, hacia Haití, Ghana y Sudáfrica -ateniéndose a los países citados por Roberto Kishimani y Evandro Mantovani.

A diferencia del Pro alcohol de los años 1970, se presencia hoy el desplazamiento de la planificación estratégica antes hecho por el Estado hacia los nuevos gestores ${ }^{21}$ conectados a los complejos empresariales, ahora organizados en red. El entrecruzamiento de esos nuevos gestores, con El Estado y los complejos corporativos, puede ser observado en el rol de los "miembros permanentes" de los "mantenedores" del ICONE, por ejemplo: "la ABAG (Asociación Brasileña de Agribusiness), miembro honorario, la ABEF (Asociación Brasileña de los Productores y Exportadores de Pollos), la ABIEC (Asociación

\footnotetext{
${ }^{21}$ Trabajo aquí en íntima afinidad con el cientista social português João Bernardo, para quien los gestores se configuran como clase social, em el mejor sentido de la expresión. Así, el capitalismo estaría constituido, desde el inicio, por tres clases fundamentales, y no dos (burguesía y proletariado). Chico de Oliveira se ha aproximado a esa formulación en sus trabajos más recientes.
} 
Brasileña de las Industrias Exportadoras de Carnes), la ABIOVE (Asociación Brasileña de las Industrias de Óleos Vegetales) y la UNICA (Unión de la Industria de Caña-de-Azúcar)”. Esas articulaciones pueden ser constatadas también en el programa, de carácter global y volcado a la producción de bioenergía, [que] tiene a Brasil como uno de los líderes. El Departamento de Energía de Estados Unidos, por medio del Joint Genome Institute (JGI), aprobó la propuesta de la red internacional Eucagen (Eucalyptus Genome Network) para el secuenciamiento completo del genoma del eucalipto. La especie escogida por Brasil es el Eucalyptus grandis, desarrollada por mejoramiento genético. La Eucagen está formada por más de 140 investigadores de 82 instituciones públicas y privadas en 18 países.

Según el investigador Dario Grattapaglia, de la EMBRAPA Recursos Genéticos y Biotecnología y coordinador de la Red Brasileña de Investigación del Genoma del Eucaliptos (Genolyptus), se trata de un proyecto global, ya que el eucalipto es plantado en más de cien países: "Uno de los desafíos para la producción sustentable de bioenergía es conocer las bases moleculares del crecimiento y adaptabilidad de plantas perennes útiles a la generación de energía". Dario Grattapaglia divide el liderazgo del proyecto con Zander Myburg, de Sudáfrica, y Jerry Tuskan, de Estados Unidos. ${ }^{22}$

\section{Las presiones que conducen a los agro combustibles}

Entre los argumentos que protagonizan el reciente debate sobre los combustibles de biomasa (etanol y biodiesel), hay el consenso de que existe una "presión social, ambiental y de los precios del petróleo" que muestra las condiciones para la expansión del sector. De hecho, desde las grandes movilizaciones de Seattle (1999) y del I Foro Social Mundial de Porto Alegre (2000), los foros internacionales que hegemonizaban el (des)orden mundial G-7, OMC, FMI y Foro Económico de Davos- pasaron a ser, literalmente, cercados (Haesbaert y Porto-Gonçalves, 2006). Las grandes movilizaciones en todo el mundo contra la invasión de Irak, en febrero de 2003, dieron muestras de la fuerza moral, mucho más que política, de esos movimientos sociales, aunque los grandes mass media siempre busquen descalificarlos. Como parte de esas luchas sociales, una serie de iniciativas del mundo empresarial comienza a ser puesta en práctica, obligándolo, así, a dejar de lado sus actividades propias para dedicarse a la responsabilidad "social y ambiental" o a patrocinar entidades no-gubernamentales. ${ }^{23}$ En los grandes mass media, sorprende en los últimos años el número de informes publicitarios patrocinados por empresas cuyos productos ni siquiera son objeto del consumo del gran público, como las propagandas de Aracruz Celulosa, que

\footnotetext{
${ }^{22}$ Disponible en:<www.cenargen.embrapa.br/cenargenda/noticias2007/ldsoft040707.pdf >. Acceso: 4 de julio de 2007.

${ }^{23}$ No es la primera vez que eso ocurre, como ya fue señalado para el caso del Informe Meadows y sus "límites del crecimiento" (Porto-Gonçalves, 1983).
} 
vende pasta de celulosa, y de la Compañía Vale del Río Dulce, que vende minerales. Paulo Scarim, geógrafo y profesor de la Universidad Federal de Espírito Santo, ha llamado la atención hacia el hecho de que las empresas estén vendiendo mucho más un modelo de desarrollo, ideología pura, y no más un producto específico.

Tal vez la más efectiva de las presiones que contribuyen para la viabilización de los agrocombustibles sea la tercera, como bien lo destaca Ignacy Sachs. Para él, el etanol es viable económicamente con los precios del petróleo a partir de US\$ 35 el barril y el biodiesel a partir de US\$ 60 - y el precio del petróleo, después de la segunda invasión de Irak, en 2003, ya no cayó abajo de los US\$ 60 el barril. Con eso, diversas medidas políticas que venían siendo tomadas tanto en Europa como en Estados Unidos comienzan a ser económicamente factibles, además de los subsidios que han sido aportados. ${ }^{24}$

\section{Exención fiscal para el etanol (euros por litro en 2005)}

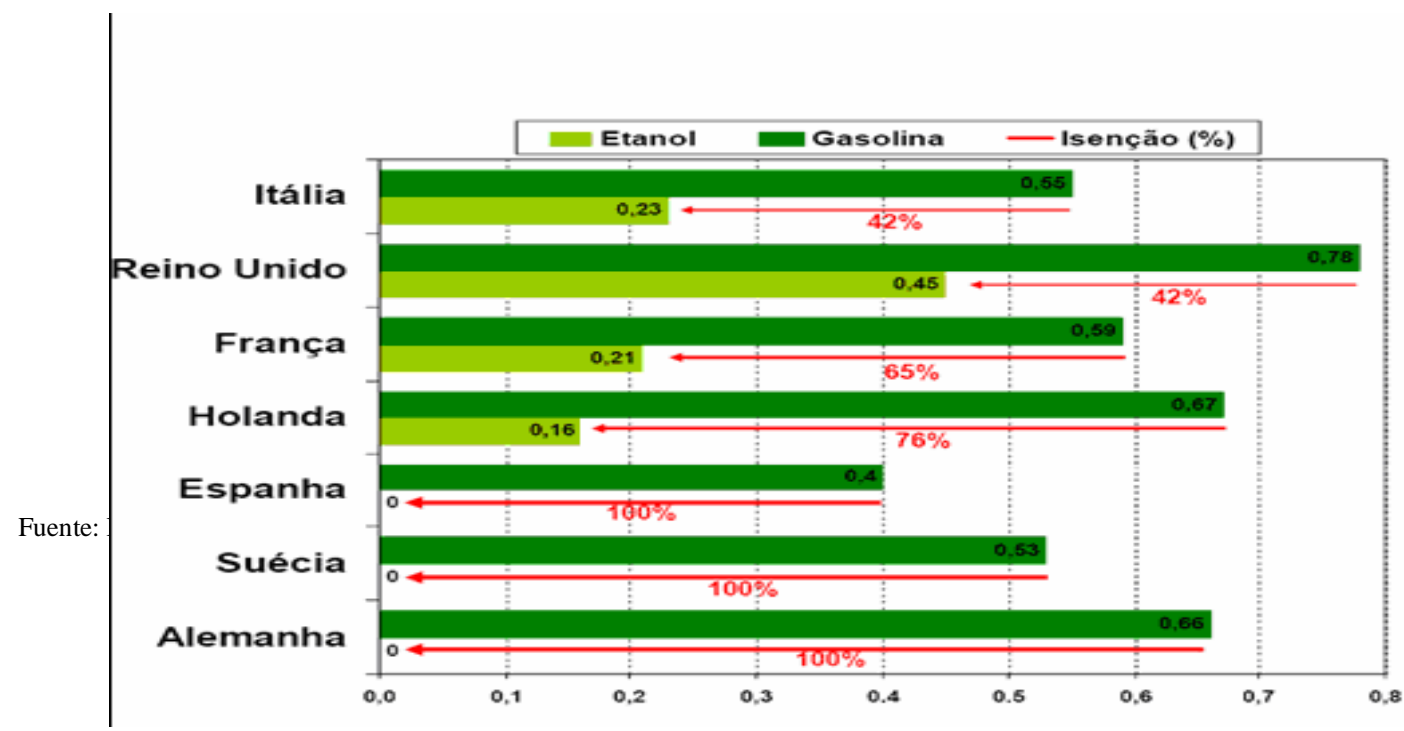

Fuente: Icone (2006)

\footnotetext{
${ }^{24}$ Según el informe del Global Subsidies Initiative, las subvenciones para los agrocombustibles sólamente en los Estados Unidos ascienden actualmente a una suma que oscila entre US\$ 5,5 billones y US\$ 7,3 billones por año, y aumentan rápidamente. "La mayoría de las actividades en cuestión de agrocombustibles en Estados Unidos y en Europa se apoya en subvenciones, y probablemente no sobrevivirían sin eso" (Koplow, 2006).
} 
Aunque no haya unanimidad en cuanto a la demanda de esos combustibles, incluso porque hay problemas de orden tecnológico que, por sus enormes implicaciones políticas, aún quedan sin ser resueltos, como lo veremos, se habla de una demanda de energía que crecería en torno a un 1,7\% al año hasta 2030, cuando sería alcanzada la marca de 15 billones tep (toneladas equivalentes de petróleo), según Evandro Mantovani.

De acuerdo con Eric Holt-Giménez (2007), director ejecutivo del Food First, los combustibles renovables deben suplir un 5,75\% de todo el combustible de transporte en Europa hasta 2010 y un 10\% hasta 2020. Estados Unidos esperan obtener 35 millones de galones al año [...]. Esas metas exceden en mucho la capacidad agrícola del Norte industrial. Europa tendría que usar un $70 \%$ de sus tierras agrícolas para combustibles. Toda la cosecha de soja y maíz de los Estados Unidos tendría que ser procesada para el etanol y biodiesel.

En las palabras de Tokar (2006),

si fueran utilizadas todas las cosechas de maíz y soja de los Estados Unidos para la producción de combustibles, se cubriría solamente un $12 \%$ de la actual demanda de gasolina (el nafta) del país y un 6\% de la necesidad de diesel. La situación en Europa no sería mejor: el Reino Unido, por ejemplo, no podría cultivar suficiente cantidad de combustibles para poner en marcha todos sus automóviles, aunque plantara la totalidad de su territorio.

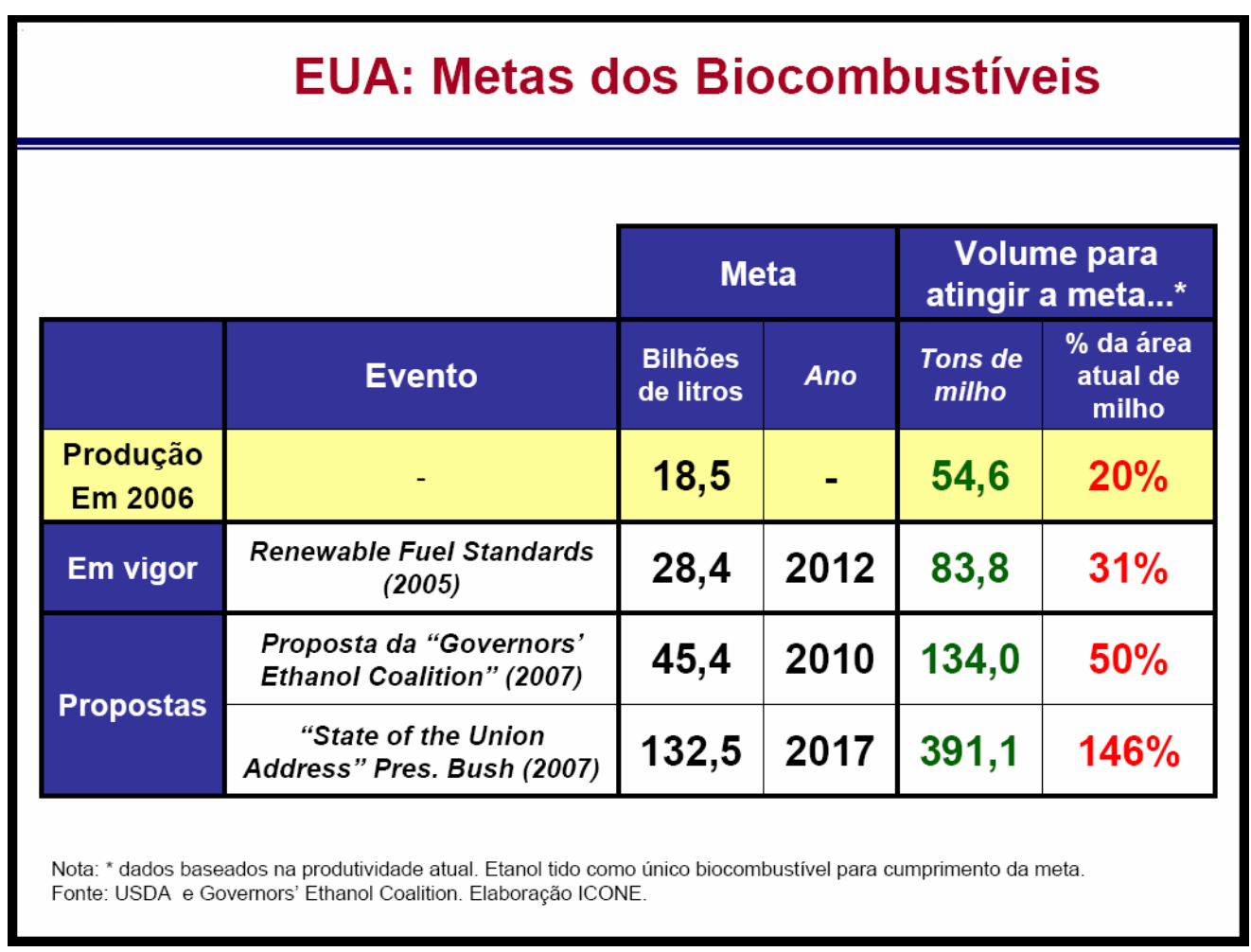


En resumen, los países del centro del capitalismo mundial no tienen cómo suplir la demanda en términos de tierras; cuando se trata de energía de biomasa, además de la extensión de tierras, hay que considerar la disponibilidad de agua y de luz solar (fotosíntesis). Es lo que parece entrever con lucidez el bloque de poder técnico-científicoagroindustrial-financiero-mediático brasileño, como se puede percibir en el dimensionamiento que el ICONE hace de las tierras disponibles en el mundo (gráfico 1) y de la disponibilidad de agua y tierras.

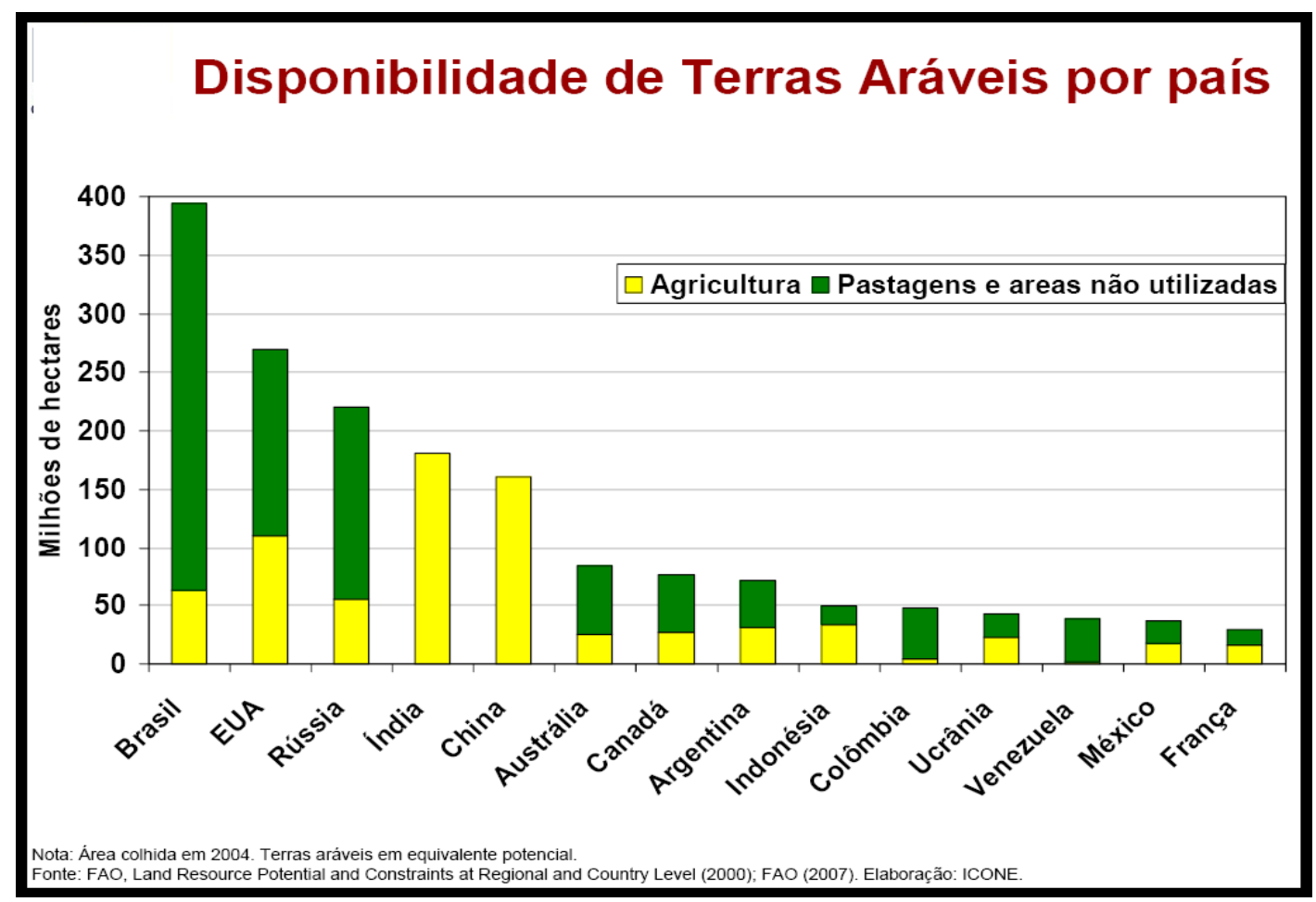

Fuente: ICONE y FAO. Elaboración: ICONE.

La experiencia acumulada por el complejo corporativo técnico-científicoagroindustrial-financiero-mediático brasileño en los últimos treinta años lo sitúa en una posición privilegiada en ese reacomodo geopolítico global. Los cuadros 2 y 3 demuestran esas ventajas, en que no deja de desempeñar un papel preponderante el desarrollo técnicocientífico, además de la renta diferencial por fertilidad de la tierra que, en virtud de la estructura política latifundista, garantiza, a precios imbatibles, grandes extensiones de tierras con menos del $12 \%$ de pendiente, ${ }^{25}$ con energía solar abundante para la fotosíntesis y la más amplia disponibilidad de agua. ${ }^{26}$

\footnotetext{
${ }^{25}$ La pendiente del terreno es fundamental para la agricultura, que depende de insumos externos, sobretodo de energia. Cuanto más acidentado es el terreno, mayor es el consumo de energía. Por eso, las grandes chapadas y los chapadões del planalto central brasileño se tornarán tan importantes para ese modelo agrícola.

${ }^{26} \mathrm{El}$ costo comparado de la tierra en la producción de soja entre Iowa, en los Estados Unidos, y Mato Grosso, en Brasil, era en 2001, respectivamente, de US\$ 350 y de US\$ 57,50 (Porto-Gonçalves, 2006, p. 231).
} 


\begin{tabular}{|l|c|c|}
\hline \multicolumn{3}{|c|}{ Cuadro 2. Etanol - costos de producción } \\
\hline Fuente & País & US\$ litro \\
\hline Remolacha & EUA & 0,53 \\
\hline Cereales & EUA & 0,45 \\
\hline Maíz & Canadá & 0,33 \\
\hline Maíz & EUA & 0,30 \\
\hline Caña de Azúcar & Brasil & 0,22 \\
\hline
\end{tabular}

Existe un intenso movimiento de capitales en todo el mundo envolviendo el complejo de poder técnico-científico-agroindustrial-financiero-mediático organizado en red, articulando lugares y regiones en una estrategia global. Según la UNICA, entidad que organiza y defiende los intereses del sector sucro alcoholero de Brasil, en 2006-07 operaban en el país 248 unidades productivas, garantizando un consumo de 150 millones de toneladas de etanol. El sector prevé una expansión para 325 unidades productivas hasta 2012, o sea, 77 nuevas unidades, más de 1,5 unidad por mes, en los próximos cinco años. La entidad informa que en el sector sucro alcoholero al menos cinco grandes grupos transnacionales ya invierten en Brasil, entre ellos la Cargill, la Evergreen, CoimbraDreyfuss, la Tereos, la Global Foods y el grupo Adeco, del empresario George Soros. ${ }^{27}$

\begin{tabular}{|l|c|c|}
\hline \multicolumn{3}{|c|}{ Cuadro 3. Produtividad - litro por hectárea } \\
\hline \multicolumn{1}{|c|}{ Fuente } & País / Región & Volumen \\
\hline Remolacha & Unión Europea & 5.500 \\
\hline Maíz & EUA & 3.100 \\
\hline Trigo & Unión Europea & 2.500 \\
\hline Caña de Azúcar & India & 5.200 \\
\hline Caña de Azúcar & Brasil & 6.500 \\
\hline
\end{tabular}

\footnotetext{
${ }^{27}$ La Adeco tiene más de 240 mil hectáreas de tierras adquiridos en Argentina, en Paraguay y en Brasil. La estratégia reciente del grupo en Argentina fue adquirir inicialmente el máximo de tierras aprovechando la crisis de 2001, cuando hubo una acentuada caída del precio, según lo declaró el propio George Soros. Aquí el sentido de las crisis como momento de oportunidad, al ejemplo de lo que se acostumbra afirmar con base en las tradiciones griega u orientales, es poco noble, sobretodo cuando se sabe de la miseria que entonces devastó el país.
} 
Indonesia y Malasia expanden rápidamente sus plantaciones de aceite de palma para suplir hasta un 20\% del mercado de biodiesel de la Unión Europea. Colombia, que ya produce más de 1 millón de litros/día de etanol, proyecta la implantación de 27 unidades productivas más hasta 2012. Según el banquero francés Olivier Combastet, del fondo de inversiones Pergam Finance, "los centenares de hectáreas de maíz y soja disponibles, por ejemplo, en Uruguay, son otro tanto de barriles estilo etanol durmiendo, cuya demanda mundial debería explorar los años venideros".

En las palabras de Dominique Guillet (2007),

British Petroleum acaba de asociarse a la Du Pont de Nemours a fin de desarrollar una nueva generación de aceite carburante vegetal. ${ }^{28}$ La Du Pont, que a principios del siglo XX era el mayor vendedor de armas en los Estados Unidos, compró la Pioneer Hibred, en 1999, empresa que dominaba la producción de semilla híbrida de maíz en el mundo, haciéndose la segunda multinacional en el ramo de semillas y la cuarta en el ramo de la agroquímica. La Toyota acaba de aliarse a la British Petroleum para producir etanol en Canadá a partir de la celulosa extraída de residuos. La Volkswagen acaba de firmar un acuerdo con la multinacional ADM (Archer Daniels Midland Company) del sector de alimentos. Ya la Royal Dutch Shell está desarrollando una segunda generación de agro carburantes y realiza pruebas de refinación a partir de lignito y de celulosa. La Cargill, otra gran multinacional del sector agroalimentario, se lanzó en la producción de diesel vegetal. ${ }^{29}$

Varios autores, como Eric Holt-Giménez, Dominique Guillet y Silvia Ribeiro, vienen señalando las graves implicaciones de esas alianzas estratégicas entre las empresas "concurrentes" en los sectores de la agroquímica, de la biotecnología, agroalimentario y las empresas del sector petrolero -contando, inclusive, con la complicidad del Estado. Así, sectores estratégicos, como los de la energía y los de producción (y comercialización) de alimentos, intermediados por el complejo técnico-científico, se quedan en las manos de unos pocos complejos corporativos, pudiendo manejar sus intereses conforme las circunstancias. Más que una previsión, esa alerta encuentra fundamento en la reciente "crisis de las tortillas" en México y, también, en las oscilaciones del programa del alcohol brasileño, en que los grandes empresarios del sector, de acuerdo con su conveniencia y con los precios, desplazaban la caña ora para la producción de azúcar, ora para la producción de alcohol. A mediados de los años 1980, la producción de automóviles movidos a alcohol entró en colapso en Brasil, pues la producción de alcohol fue prácticamente abandonada, una vez que los precios no compensaban vis-à-vis los del azúcar.

\footnotetext{
${ }^{28}$ La British Petroleum recientemente puso a disposición de la Universidad de California nada menos que US\$ 500 millones para pesquisas.

${ }^{29}$ Disponible en: <www.legrandsoir.info/article.php3?id_article=5055> Acceso: 26 de julio de 2007.
} 


\section{Brasil: potencial para expansión de la producción del etanol en la visión de los agro-negociantes}

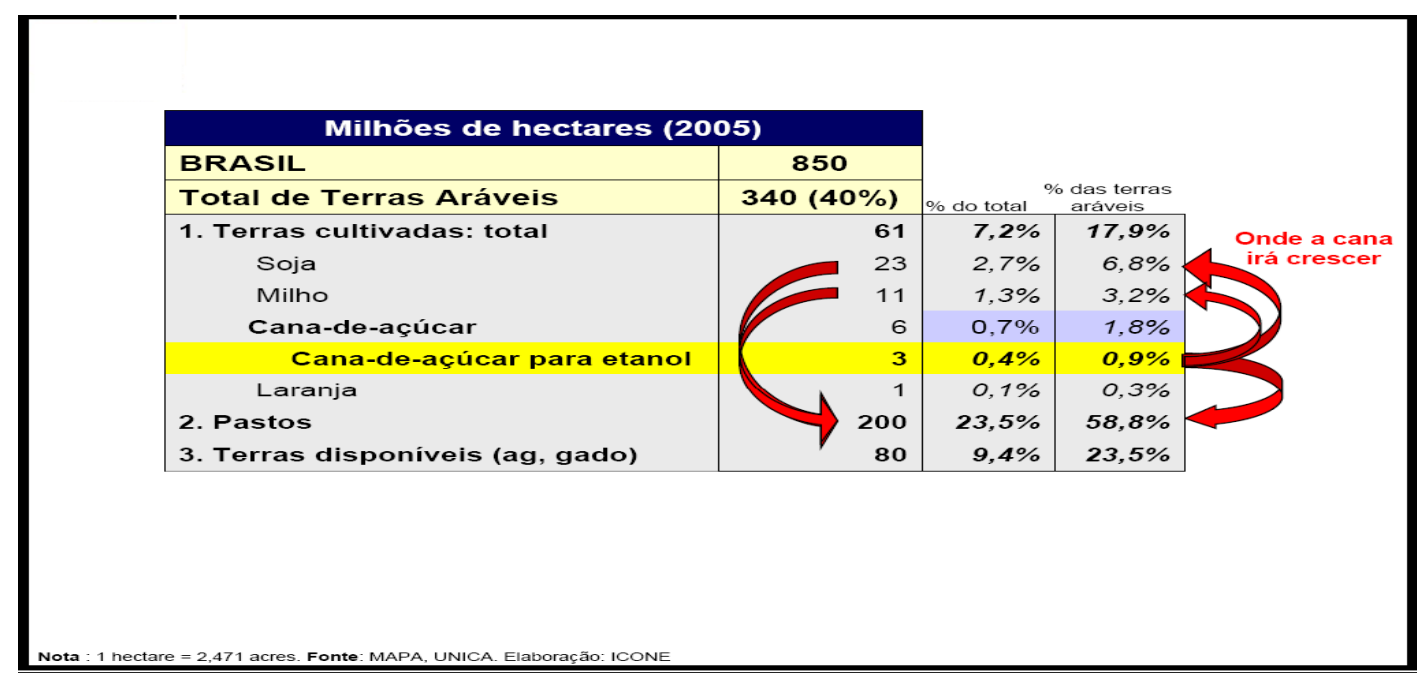

La disputa por tierra y agua entre la producción de alimentos y la de esos combustibles no es para el futuro. Silvio Porto, director de la Compañía Nacional de Abastecimiento (CONAB - Brasil), admitió que la caña-de-azúcar está quitando áreas al maíz y a la soja, en Mato Grosso do Sul, en Paraná y en Minas Gerais. Es la primera vez que un técnico del gobierno reconoce la presión ejercida por la expansión de la caña sobre áreas productoras de granos. "La entrada de la caña de forma más efectiva en el CentroOeste podrá volver a causar nueva presión en la región de Amazonia Legal por nuevas áreas agrícolas o áreas de pastizales. Efectivamente, la caña está tomando áreas del maíz y de la soja" ( $O$ Estado de S. Paulo, 4 jul. 2007). La constatación es coherente con los análisis que hace Roberto Rodrigues, ex-ministro de la Agricultura, que viene insistiendo que el problema para la expansión de los agrocombustibles no es la tierra, sino la logística. Él prevé que en los prójimos veinte años el área para el cultivo de la caña-de-azúcar va a aumentar el equivalente a 1 millón de hectáreas por año -o sea, aumentará 20 millones de hectáreas (Rodrigues, 2006), conforme lo demuestra el cuadro anterior. En ese mismo cuadro, como lo indica el movimiento de las flechas, se tornan evidentes las regiones hacia donde se van expandir los monocultivos de soja, maíz y caña en la visión de los agro negociantes, aunque sea, sobre pastos y estos sobre los cerrados aún remanentes y la floresta amazónica, lo cual no se dice. Los pastizales son el verdadero frente pionero de ese ciclo de violencia y devastación que se reproduce en las últimas décadas, como se puede notar en el gráfico a continuación, en que los pastizales crecen más que la agricultura. 


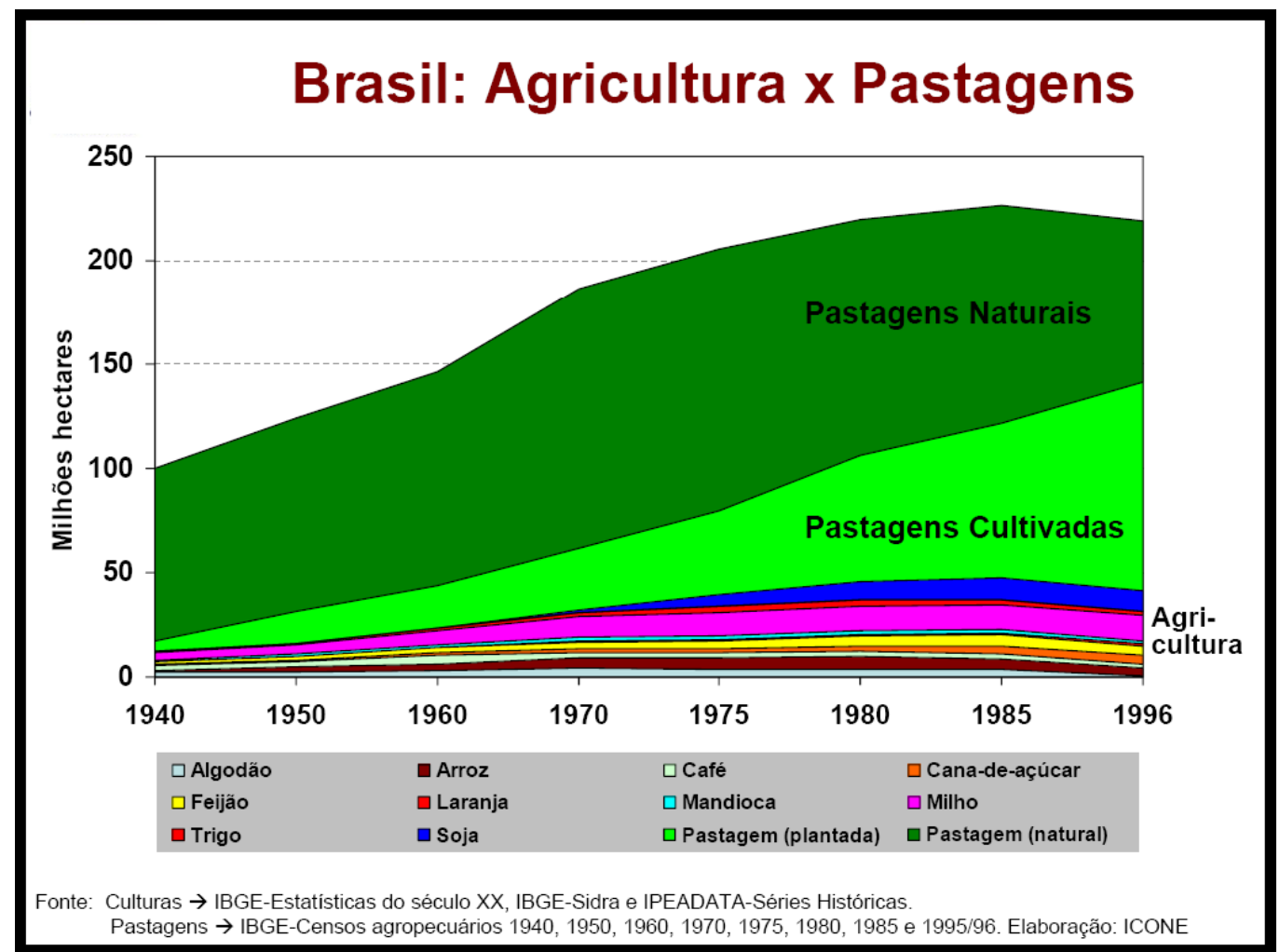

Cuando se observa el mapa con las unidades de procesamiento sucro alcoholero (ver mapa a continuación), se percibe que las 77 nuevas unidades productivas están todas localizadas en el centro geoeconómicamente más dinámico del país: 35 en São Paulo, 18 en Minas Gerais, 10 en Goiás, 9 en Mato Grosso do Sul, 4 en Paraná y 1 en Río de Janeiro. Buena parte de esas áreas está ocupada con pastizales y ganado ${ }^{30}$-como, de hecho, los ideólogos de la ABAG, entre ellos Marcos S. Janks y Roberto Rodrigues, vienen preconizando-, conforme se destaca en el gráfico en que se apunta hacia dónde deben avanzar los grandes monocultivos de caña, es decir, sobre áreas de pastizales. Sustituir pastizales por caña no es lo mismo que sustituir la soja o el maíz, lo que también está aconteciendo, pues implica el desplazamiento del ganado hacia otras áreas. En un levantamiento de campo realizado en fines de julio de 2007 en la Amazonia matogrossense, en el Valle del Araguaia, registré un aumento en el arrendamiento de tierras para el ganado entre un $25 \%$ y un $30 \%$ en un año. En Goiás, ya se ven manifestaciones de los empresarios del sector de pollos y de cerdos, preocupados con la elevación de los precios del maíz, que corresponden, en la media, a un $40 \%$ de los costes de producción del pollo y del cerdo.

\footnotetext{
${ }^{30}$ Brasil posee un rebaño bovino de 205 millones de cabezas, que ocupan cerca de 200 millones de hectáreas de tierras.
} 


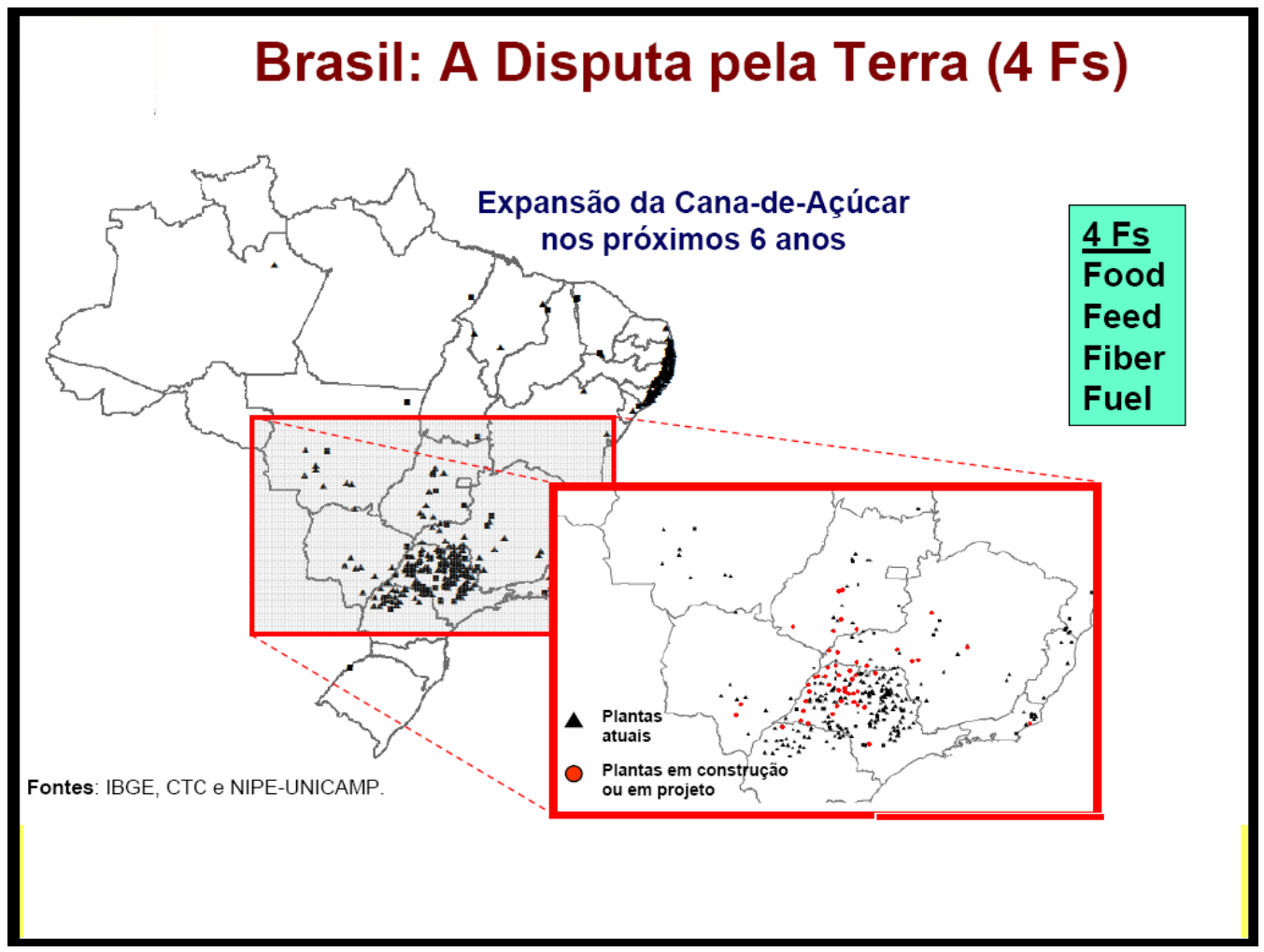

Así, tanto por los hechos ya constatados por investigaciones independientes como por los propios argumentos de los principales ideólogos de la expansión de la agro energía, se puede observar la presión sobre las áreas de frontera -sobre todo los cerrados y la Amazonia-, la cual se intensificará, si no se hacen sentir en los hechos las presiones sociales y ambientales.

\section{Implicaciones políticas y sociales de la revolución tecnológica en torno a los agro combustibles}

Aún creyendo que es exagerada la idea de que estamos en frente de una "transición energética", como es pregonado por el sector de los agro negociantes de energía, aunque algo en esa dirección sea necesario, es preciso estar atento a las profundas implicancias políticas y sociales de la bifurcación tecnológica que está por ser decidida a espaldas de un debate amplio y verdaderamente democrático.

Todo indica que el bloque de poder que busca afirmarse por la agro energía haya logrado una enorme ventaja política por medio de la innovación tecnológica de los "motores flex", que permiten usar indiscriminadamente gasolina o alcohol (ver gráfico a continuación). Delante de eso y con la fusión y alianzas estratégicas entre empresas "concurrentes" del sector de alimentos y energía, inclusive del petróleo, el poder de esas 
empresas se hace imponderable, a no ser que se revocara la ley general de la acumulación del capital y se las obligara a subordinar el valor de cambio al valor de uso -0 , en otras palabras, se les obligara a subordinar sus intereses de acumulación a los intereses de la humanidad o del planeta.

\section{Evolución de las ventas de automóviles por tipo de combustibles - Brasil 2003-06.}

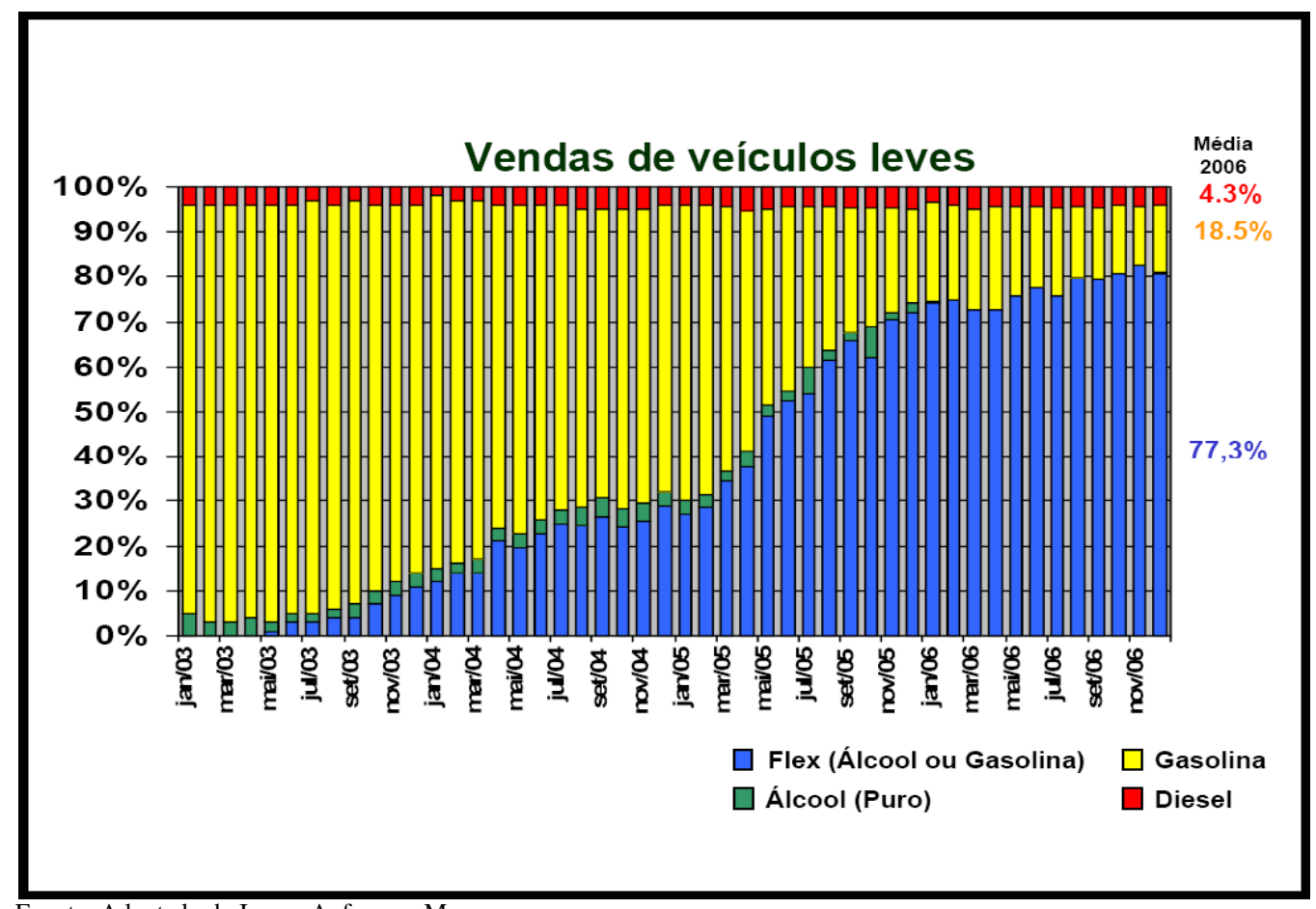

Fuente: Adaptado de Icone, Anfavea y Mapa.

Pero no paran ahí las implicaciones de los cambios en las relaciones sociales y de poder mediante las tecnologías engendradas por el nuevo bloque de poder en conformación: -la burguesía organizada en red nacional-global como complejo corporativo técnicocientífico-industrial- financiero-mediático. Según investigadores de la EMBRAPA, en los próximos cinco años serán decididas las especificaciones y normativas técnicas de los motores que van a determinar la calidad físico-química de los carburantes a ser utilizados. $^{31}$ La Petrobrás, por ejemplo, ha sido extremadamente conservadora en la

\footnotetext{
${ }^{31}$ En este momento, la caña es la mejor solución técnica para la producción del etanol, lo cual, en el Brasil, significa consagrar a las oligarquías latifundistas en el poder hace cinco siglos. En el caso del biodiesel, la soja es la que presenta la mejor ecuación de costos y produtividad, también termina afirmando un complejo corporativo que tiene por base una concentración de tierras sin precedentes em el país, sobretodo en su expansión por la región de los cerrados.
} 
determinación de permitir sólo la mezcla del $2 \%$ de óleo vegetal al óleo convencional, mientras ya permite una mezcla de más del $20 \%$ de etanol a la gasolina porque, en ese caso, ya estarían bien resueltos los problemas técnico-políticos, sobre todo en la industria automotriz con los "coches flex". ${ }^{32}$ Finalmente, son más de veinte las especies de plantas con potencial para la producción de óleo carburante, entre las cuales están el ricino, el dendé, la soja, el cacahuete, la colza, el girasol, el maíz, el buriti y el babaçu. Por más que se propaguen las ventajas de los países con recursos naturales disponibles (tierras, energía solar y agua) y aún con el dominio de la tecnología para su utilización, como en Brasil, el poder de definir esas determinaciones tecnológicas para el uso generalizado de los motores está en los grandes centros geopolíticos de los países imperialistas que ejercen prácticamente el monopolio de la investigación científica (Mari, 2000; Porto-Gonçalves, 2006). Considérese además que, mientras la industria exige parámetros universales de medida lo que, en parte, fue conseguido mediante la matematización de la física, de la química, de la biología molecular y de la economía, lo mismo no puede ser dicho de la agricultura, en que las soluciones exigen considerar las condiciones locales y los puntos de vista políticos, sobre todo nacionales. Eso demanda de cada protagonista, inclusive a los sectores subalternos, articularse a la escala global.

El control del sector de semillas se vuelve, así, estratégico para definir el dominio (político) del mercado. He aquí la razón del entrecruzamiento de empresas tradicionales del sector del petróleo y del sector automotriz con el de las semillas, es decir, con el de la biotecnología, como lo hemos visto involucrando a British Petroleum, Toyota, Volkswagen, Shell, Pioneer Hibred, ADM y Cargill, entre otras.

En ese contexto, las investigaciones de los OLMs ganan enorme relevancia, en la medida en que permiten un control técnico-industrial de las semillas, lo cual, por su parte, puede garantizar la homogeneidad físico-química de los óleos carburantes. Es, en la mejor de las hipótesis, pueril el abordaje que intenta incorporar al mercado sectores campesinos por intermedio del biodiesel, o mejor, subordinar los campesinos a ese complejo de poder. Al final, sin un profundo cambio en las relaciones sociales y de poder por medio de la tecnología que devuelva a los campesinos, como mínimo, el control de su propia reproducción mediante el control de las semillas, lo que el complejo de poder hegemónico intenta de cualquier forma evitar, la humanidad tenderá a ver su destino controlado por un

\footnotetext{
${ }^{32}$ Ha existido una fuerte presión de los grandes productores brasileños para ampliar el uso de esa mezcla. Afirman tener un enorme potencial de producción que no está siendo aprovechado en la mezcla que, según ellos, podría alcanzar hasta 30\%. Dicen que vienen utilizando el óleo en los equipamientos en sus propiedades, independientemente de la autorización gubernamental.
} 
verdadero oligopolio.

Cabe aquí destacar las implicaciones epistémicas y políticas de lo que está en juego con lo que denominamos OLMs (y no OGMs). ${ }^{33}$ Con los OLMs cambia el lugar de la producción de conocimiento en un sector fundamental para la existencia humana, la agricultura y la creación de animales, y lo que dice respecto a la reproducción energéticoalimentaria de nuestra especie. Así como el conocimiento es, tal como el alimento, condición necesaria para la reproducción -asimismo, todo modo de producción de alimento es un modo de producción de conocimiento-, con el desplazamiento de los OGMs, como producción de cultivares para los OLMs, asistimos al desplazamiento del locus de poder que pasa de los campos y de los campesinos, inclusive de los pueblos originarios, hacia los grandes laboratorios del complejo técnico-científico-agroindustrial-financiero-mediático. La diversidad cultural tiende a ser amenazada. Todo indica que el destino de la humanidad y del planeta dependerá de la solución de esa lucha que, cada vez más, exige la atención de todos.

\section{¿Un nuevo ciclo del desarrollo rural?}

Varios autores, como Ignacy Sachs, destacan que estamos delante de un nuevo ciclo de desarrollo rural rumbo a una nueva civilización de la biomasa. De hecho, en el mundo rural se dio una gran bifurcación con la llamada Revolución Verde, cuyos efectos pudimos observar en las últimas cuatro décadas en todo el mundo, sobre todo por el intenso éxodo rural, cuando fue impulsada una verdadera agricultura sin agricultores. Sin embargo, lo que viene siendo propuesto por el complejo de poder técnico-científico-agroindustrialfinanciero-mediático es una nueva bifurcación en el interior de la Revolución Verde, al intentar imponer su "transición energética". En síntesis, la revolución (en las relaciones sociales y de poder) industrial, al extender al campo su matriz energética, puso, de cierta forma, el Sol de ayer, la biomasa fósil mineralizada hace millones de años atrás (el carbón y el petróleo), al servicio de la producción de alimentos, con el uso generalizado de máquinas y fertilizantes. Lo que se engendra ahora es una profunda transformación en las relaciones sociales y de poder, de implicaciones ecológicas planetarias sin igual, en la exacta medida

\footnotetext{
33 El concepto de organismo genéticamente modificado (OGM) es impreciso desde el punto de vista científico, pues, rigurosamente, toda la evolución de las especies implica mudanza genética. El proceso de especiación ocurre, siempre, por modificación genética, como proceso no-intencional. Los cultivares, a su vez, son, desde siempre, OGMs, en la medida en que son creaciones humanas coevolucionando con procesos naturales durante tiempos largos (intención + naturaleza). Lo que está en debate, hoy, no son los OGMs, y sí los OLMs (organismos laboratorialmente modificados), cuyo proceso de creación no se da de modo libre en la relación de los agricultores con la naturaleza. Aquí, ya no estamos más delante de la agricultura, y sí del agronegocio, como le gusta autodenominarse al complejo técnico-científico-empresarial.
} 
en que es la agricultura la que se pone a servicio de la producción de combustibles - ¡no más el petróleo al servicio de la producción de alimentos, sino por el contrario, la agricultura al servicio de la producción de combustibles!

Según la Organización de las Naciones Unidas (ONU), en 2005 más de la mitad de la población mundial era rural (un 51\%). Todo indica que hasta 2010 la población urbana alcance la simbólica marca del 50\% de la población mundial.

\section{Evolución de la población urbana y rural en el mundo - 1950-2010.}

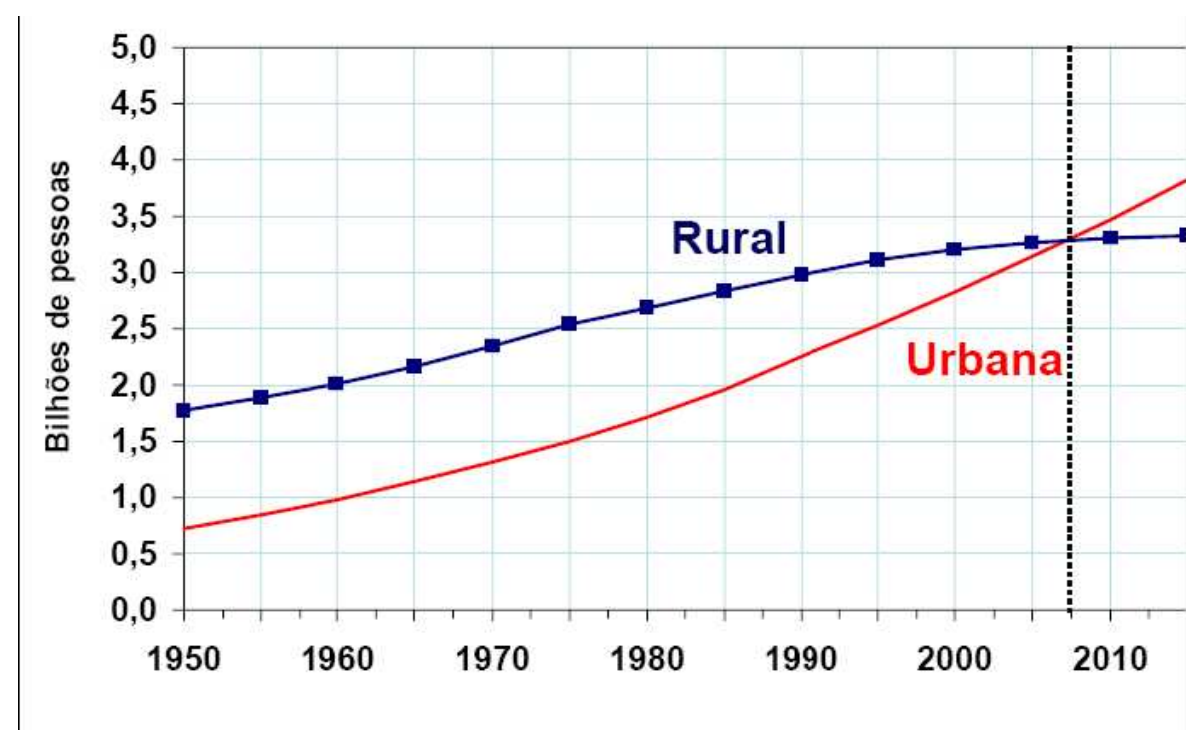

No deja de ser sorprendente que hayan sido necesarios más de doscientos años, desde la revolución (en las relaciones sociales y de poder) industrial, para que ese cambio ecológico global desde lo rural a lo urbano haya ocurrido, teniendo en cuenta el discurso urbano céntrico hegemónico que parecía indicar que el mundo ya sería urbano hace mucho tiempo. Lo más grave, sin embargo, es que del $49 \%$ de la población urbana indicada por la ONU para el año de 2005, nada menos que un 70\% están en América Latina, en África, en el Oriente Medio y en Asia, viviendo en condiciones muy distantes de aquellas pregonadas por los ideólogos que hablan de la inexorabilidad de esa transición demográfica rumbo a lo urbano y del avance civilizatorio que la urbanización traería. Solamente un $25 \%$ de la población mundial, aproximadamente, vivirían, hoy, bajo un modo de vida urbano tal como es idealizado, o mejor, ideologizado, si consideráramos los datos de Samir Amin (ver el cuadro a continuación). 


\begin{tabular}{|l|c|c|c|}
\hline \multicolumn{4}{|c|}{$\begin{array}{c}\text { Clases sociales de la población urbana mundial } \\
\text { (millones de habitantes) }\end{array}$} \\
\hline & Centro & Periferia & Mundo \\
\hline Clases medias y ricas & 330 & 390 & 720 \\
\hline Clases populares Estabilizados & 390 & 330 & 720 \\
\hline Precarios & 270 & 1.290 & 1.560 \\
\hline Total clases populares & 660 & 1.620 & 2.280 \\
\hline Total general & 990 & 2.010 & 3.000 \\
\hline
\end{tabular}

Fuente: Amin (2003)

Es necesario considerar que: (1) hoy no es posible a los países que muestran la mayor parte de la población rural, sobre todo en Asia y en África y en algunos países de América Latina, la misma solución que los europeos encontraron para sus 60 millones de emigrantes enviados hacia todo el mundo a lo largo del siglo XIX y de las primeras décadas del XX; (2) la situación precaria de la mayor parte de la población urbana del mundo, como se puede ver en la tabla anterior; (3) que la capacidad de generar empleos por la industria es cada vez menor, lo que tiende a agravar ese cuadro -todo esto muestra los graves efectos de las transformaciones en curso, sobre todo si el principal móvil de las transformaciones es continuar siendo las fuerzas políticas que están en el flujo y el reflujo del mercado.

De hecho, para buscar un nuevo ciclo de desarrollo rural diferente de lo que las fuerzas hegemónicas vienen indicando, se requiere osadía epistémica y política para hacer valer "las presiones sociales y ambientales" además de aquella que, hasta aquí, parece ser la presión más fuerte en la busca de alternativas energéticas a los fósiles, cual es, el elevado precio del petróleo. En el análisis del consumo de energía en la agricultura, la diferencia entre el sistema agrícola industrial y el tradicional es escandalosa. Es lo que revela la FAO. Según cálculos de la organización, en promedio los agricultores de los países industrializados gastan cinco veces más energía comercial para producir un kilo de cereales que los agricultores de África. Analizando cultivos específicos, las diferencias son aún más espectaculares: para producir un kilo de maíz, un agricultor de Estados Unidos utiliza 33 veces más energía comercial que su vecino o vecina tradicional de México. Para producir un kilo de arroz, un agricultor en Estados Unidos gasta ochenta veces la energía comercial usada por un agricultor tradicional de las Filipinas. ${ }^{34}$

En Brasil, la hegemonía de los grandes empresarios latifundistas del monocultivo construyó un mito sobre la superioridad de las grandes propiedades. Sin embargo, conforme el geógrafo Hervé Théry, aún considerando la lógica económica, sorprende el hecho de que Francia obtiene más divisas con la exportación agrícola que Brasil, país que se presenta como uno de los grandes exportadores mundiales. Y Francia tiene una estructura agraria con propiedades que, en el contexto brasileño, serían consideradas minifundios o, a lo

\footnotetext{
${ }^{34}$ FAO, The energy and agriculture nexus, Roma, 2000, tablas 2.2 y 2.3. Disponible en: <http://tinyurl.com/2ubntj>.
} 
sumo, pequeñas propiedades. Como se puede apreciar, lo que viene siendo llamado agregación de valor necesita considerar otros valores, que acaban implicando también precios, como las tradiciones culturales que, en el caso de Brasil, bien podrían ser los productos del mundo colonial del Sur, o los de la cocina mineira, de la capixaba (guiso de pez), o de la nordestina. Pero tener eso en cuenta es considerar también a sus creadores, y, así, la justicia social y la diferencia cultural se aproximan una vez más.

Además, hay desperdicio de energía en el mundo con el simple tráfico de mercancías agrícolas, donde, además del consumo de energía en el transporte propiamente dicho, muchos productos tienen que ser frigorizados, lo que también exige un elevado consumo de energía. Yo he visto pollos producidos en Santa Catarina siendo transportados en un camión en la Transamazónica, por más de 3 mil kilómetros, configurando no sólo una irracionalidad ambiental, sino también una agresión a los habitantes de la región amazónica, como si ellos no supieran siquiera criar gallinas. En el mismo sentido, "todos los días, 3.500 cerdos viajan desde distintos países europeos hasta España, mientras que en el mismo día otros 3.000 cerdos viajan en la dirección opuesta. España importa 220 toneladas de patatas diariamente del Reino Unido, mientras exporta 72 toneladas de patatas todos los días [...] para el Reino Unido" (Grain, 2007).

El Instituto Wuppertal calculó que la distancia recorrida por los ingredientes de un yogur de frutas vendido en Alemania (y que podría ser fácilmente producido allá mismo) no es menor que 8 mil kilómetros. ${ }^{35}$ En el sistema alimentario industrializado, se gastan como mínimo quince calorías para producir y distribuir un alimento que tiene el valor de una caloría. Nada de eso sería necesario, realmente. El Consejo Mundial de Energía estima que la cifra total de energía requerida para cubrir las necesidades básicas es equivalente a solo un $7 \%$ de la actual producción mundial de electricidad. ${ }^{36}$

Por lo tanto, un nuevo ciclo de desarrollo rural implica, al mismo tiempo, una nueva relación entre los lugares y volver a pensar el sentido que se creía inexorable del cambio ecológico de lo rural y de lo urbano, en un mundo donde lo urbano trasciende la ciudad y lo rural no se resume en lo agrícola.

\footnotetext{
35 Gustavo Duch Guillot, director de Veterinarios Sin Fronteras (Barcelona, 2006). Disponible en: $<$ http://tinyurl.com/2mlprh>.

${ }^{36}$ The challenge of rural energy poverty in developing countries. Disponible en: $\langle\mathrm{http}: / /$ tinyurl.com/2vcu8v $\rangle$.
} 
Para eso, tradiciones de pensamiento que parecían superadas se vuelven actuales para el debate y la crítica, como es el caso de los fisiócratas, que siempre resaltaron el papel de la naturaleza en la creación de riqueza. Marx en su Crítica al programa de Gotha, destacó lo mismo, diciendo que, si el trabajo era el padre, la naturaleza era la madre de la creación de riqueza, aunque esa afirmación no haya tenido mayores consecuencias en la tradición marxista. Aún en la industria, la naturaleza continúa contribuyendo para la creación de riquezas, como diría un buen fisiócrata, pues el múltiplo de equivalente de caballos contenido en las moléculas de carbono -de ahí el concepto caballo-vapor (horsepower hp)-, por más que sea un descubrimiento científico, no es un producto ni de la ciencia ni de la técnica. Finalmente, son necesarias una calidad y una cantidad de energía sin par, además de algunos millones de años, para producirlas como carbón, petróleo y gas; por esa razón, son llamados recursos naturales no-renovables, aunque esa noción sea relativamente reciente y se deba al movimiento ambientalista.

\section{América Latina y Caribe en la nueva geografía política de la energía}

\section{La perspectiva hegemónica}

El cuadro geopolítico latino-americano ya venía siendo alterado desde 1989 con la emergencia de movimientos populares anti neoliberales, inclusive provocando la primera caida de un gobierno democráticamente electo, ${ }^{37}$ Raúl Alfonsín en Argentina, aunque al costo de sufrir masacres, por ejemplo lo que fue conocido como el Caracazo, ocurrido en febrero de aquel año en Venezuela. Otros momentos clave de ese juego geopolítico visto a partir de las luchas de clases fueron: (1) las marchas por la Dignidad y por el Territorio realizadas al mismo tiempo en Bolivia y en el Ecuador en 1990; (2) la iniciativa de los gobiernos de los Estados Unidos, de Canadá y de México por medio del Tratado de Libre Comercio de América del Norte (Nafta); y (3) la sorprendente respuesta dada por el movimiento indigenista del sur de México, por intermedio del zapatismo, en $1^{\circ}$ de enero de 1994, cuando se suscribía aquel tratado. Se destaca, aún más (4) la contra-respuesta dada por los gobiernos de México y de los Estados Unidos al zapatismo, con el Plan Puebla Panamá después de la elección de Vicente Fox. Se registra también (5) que el ALCA ya venía siendo gestado, ${ }^{38}$ aunque de modo sigiloso, desde 1994, pero sólo se hizo público a

\footnotetext{
${ }^{37}$ Hasta 2005, fueron dieciseis los presidentes elegidos en América Latina que cayeron, y no debido a golpes de Estado, aunque haya habido tentativas de ese tipo en Venezuela y en Haití, habiendo sido consumada en este último.

${ }^{38}$ Considérese, para mayor precisión y comprensión de ese juego geopolítico, que el Alca pasa a ser buscada después que los Estados Unidos se vieron derrotados en su tentativa para implantar un acuerdo multilateral de inversiones, de ahí su búsqueda de la formación de un bloque regional, el Nafta y, después, el Alca.
} 
fines de los años 1990, cuando las contradicciones entre los propios sectores dominantes hicieron trascender informaciones a la opinión pública. Además del propósito de acuerdos normativos para el "libre comercio", (6) está en curso un gran proyecto, Iniciativa para la Integración de la Infraestructura Regional Suramericana (IIRSA), pensado exactamente para ofrecer la infraestructura al gran capital, revelando en este caso una iniciativa geopolítica en la cual se pueden ver los intereses específicos de un bloque de poder que busca afirmarse a partir de un complejo geopolítico suramericano, con Brasil al frente, aunque con alianzas con el gran capital de los países centrales. Los agros negociantes y las grandes empresas de construcción civil son los principales impulsores de la IIRSA. ${ }^{39}$

Sin embargo, fue fundamentalmente después de (7) la elección de Hugo Chávez, en 1998, sobre todo por los imprevisibles desdoblamientos de la Revolución Bolivariana, que apuntaron hacia un nuevo cuadro geopolítico, aunque no se deba menospreciar la devolución del canal del Panamá, en 1999, (8) a lo que se siguió la estrategia de los Estados Unidos de crear bases militares por toda la región (ver Ana Ester Cecean), además del Plan Colombia (y su anexo posterior, la Iniciativa Regional Andina). Ya en 2001, cuando los precios del petróleo comenzaron a dispararse, el gobierno de Chávez estableció una política de precios diferenciados para los pequeños países de América Central y del Caribe, incluso Cuba, lo que le valió advertencias de la Organización de los Estados Americanos (OEA). ${ }^{40}$

Finalmente, a partir de la elección de Chávez y de su proyecto bolivariano, de las movilizaciones de los sectores subalternos, sobre todo después de Seattle (1999), del I Foro Social Mundial (Porto Alegre, 2000), de la Guerra del Agua (Cochabamba, Bolivia, 2000), del derrocamiento de la experiencia neoliberal en Argentina (diciembre de 2001), seguida por el "que se vayan todos", y de la Guerra del Gas (Bolivia, 2003), se juntaba una política de Estado involucrando a uno de los principales proveedores de petróleo para los Estados Unidos. Poco a poco, a partir de iniciativas del gobierno venezolano fue ganando fuerza la Alternativa Bolivariana para Américas (Alba). A fines de 2005, la victoria de Evo Morales, en Bolivia, dio más consistencia a las luchas de los sectores subalternizados, al alcanzar un país que dispone de una de las más importantes reservas de gas natural, preocupando a sectores de las clases dominantes brasileñas. La derrota del proyecto de la ALCA puso fin a una alianza que incluía grandes grupos empresariales no sólo de los Estados Unidos, sino también de América Latina, a lo que el gobierno estadounidense contrapuso una serie de

\footnotetext{
${ }^{39}$ Que yo sepa, por primera vez en la historia de América Latina se pueden comprar en quioscos de periódicos brasileños revistas específicamente dedicadas a los negocios en América Latina.

${ }^{40}$ Es que en los Acuerdos de San José, de la OEA, las relaciones multilaterales no pueden incluir a Cuba. Inmediatamente el gobierno venezolano retiró a Cuba del propósito multilateral y estableció un convenio específico com aquel país, escapando, así, a las sanciones de la OEA.
} 
tratados bilaterales, bajo la denominación de Tratados de Libre Comercio (TLCs).

En ese contexto surge una nueva alianza estratégica de los sectores hegemónicos, bien resumida en la frase de Jeb Bush "Del ALCA al alcohol", y basada en la Asociación Interamericana de Etanol. Pasemos la palabra a uno de los principales ideólogos de esa estrategia, Marcos S. Janks, consultor del ICONA y hoy presidente de la UNICA, entidad que articula los intereses de los mayores productores del sector sucro alcoholero, en un artículo publicado emblemáticamente bajo el título "Del ALCA hacia el Alcohol", en 4 de marzo de 2007, en el periódico O Estado de S. Paulo, órgano de prensa que, como se señaló, está asociado a la ABAG:

La visita de Bush puede ser un primer paso en la dirección correcta. Todo indica que el presidente americano viene a Brasil para suscribir un memorándum de comprensiones que contendrá: 1 - el desarrollo de proyectos comunes de investigación de etanol de celulosa; 2 - el establecimiento de normas internacionales para los commodities, ya que el buen funcionamiento de cualquier mercado depende de patrones universales; 3 - la decisión de desarrollar proyectos que apoyen la expansión del producto en terceros mercados, principalmente en América Central y en el Caribe. El Departamento de Estado, sin embargo, fue taxativo en afirmar que el tema del "acceso a mercados" no estará sobre la mesa. [...]

El ALCA (Área de Libre Comercio de Américas) fue enterrada porque no hubo suficiente diálogo y comprensión entre Estados Unidos y Brasil, países que fueron indicados como co-presidentes del proceso negociador justamente para hacer avanzar el bloque. En lugar de el ALCA, se instaló una miriada de pequeños acuerdos bilaterales y sub-regionales en todas las direcciones, de pequeño alcance y repletos de asimetrías, inmediatismos y confusiones. [...]

El alcohol representa una oportunidad de oro para que Estados Unidos y Brasil intenten entenderse y coordinen el crecimiento armónico de este nuevo paradigma de los sectores agrícola y energético. Comencemos con estudios detallados cubriendo las áreas de investigación, producción, infraestructura, potencial energético e impactos sociales y ambientales. Enseguida, iniciemos proyectos ambiciosos de investigación conjunta en nuevas tecnologías agroindustriales y automotrices y fijemos patrones globales para los commodities agroenergéticos. Vamos también a cooperar en la expansión de la oferta y de la demanda en terceros países. Avancemos igualmente con inversiones conjuntas en producción e infraestructura en los dos países y luchemos para establecer políticas más coherentes, volcadas hacia los vectores señalados anteriormente, incluyendo, desde ya, el espinoso tema del proteccionismo, aunque sólo en una nota de pié de página en este primer momento.

Aquí, como vemos, vuelven a encontrarse fuerzas políticas tradicionales en el bloque de poder de los diferentes países latino-americanos y que se forjaran protagonizando una 
división internacional del trabajo en que los recursos naturales de la región son explotados buscando la exportación. En el golpe que depuso el presidente J. B. Aristide, en Haití, esas fuerzas comenzaron a reaproximarse y, en el caso brasileño, en una clara continuidad del gobierno de Lula la lucha por un lugar en el Consejo de Seguridad de la ONU, iniciada bajo la gestión de Fernando Henrique Cardoso. Ahora, además de las iniciativas ya señaladas de investigaciones junto a la Unión Europea y al gobierno estadounidense, esos grandes grupos del complejo técnico-científico-agroindustrial-financiero-mediático delinean una nueva estrategia geopolítica en la que Brasil viene intentando sacar provecho de los TLCs que el gobierno estadounidense puso en práctica como primera alternativa a la derrota del proyecto ALCA, sobre todo en gobiernos de los países de América Central y del Caribe.

\section{Agua y tierras disponibles por país en la visión de los agro negociantes}

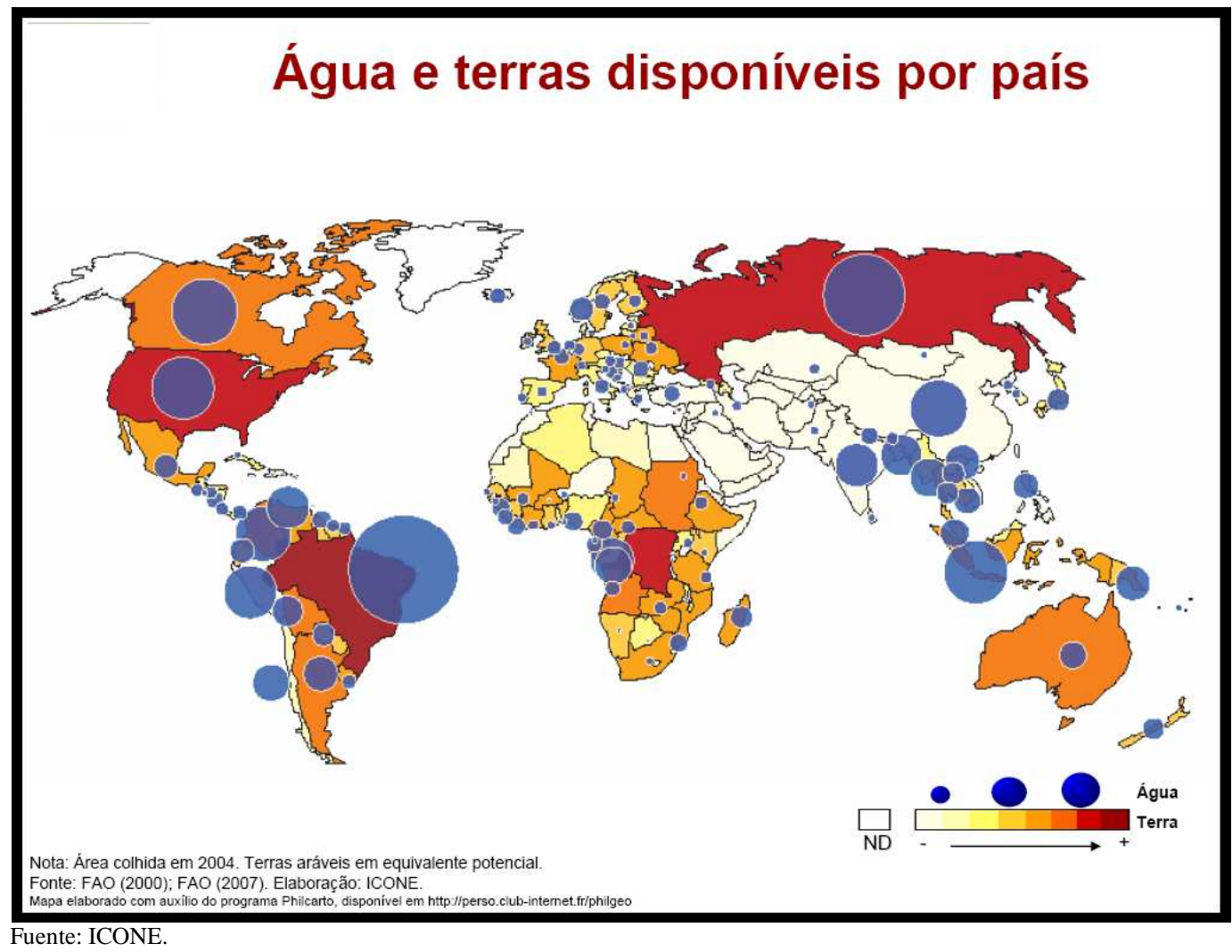

En el mapa anterior, que integra la visión que viene siendo construida por los think thank que subsidian los agro negociantes, América Latina, especialmente América del Sur, aparece destacada por su amplia disponibilidad de agua y tierras. Brasil obtiene un lugar especial no sólo por su extensión territorial, 850 millones de hectáreas, sino también por el 
elevado nivel de desarrollo técnico-científico alcanzado particularmente en el área de combustibles de biomasa (etanol y biodiesel).

En lo que concierne al agua, el Instituto Internacional para el Manejo del Agua (IWMI - International Water Management Institute), en su informe de marzo de 2006, afirmó que la fiebre por los "biocombustibles" podría empeorar la crisis de agua en el continente. En otro documento, concluía ser "poco probable que las economías de rápido crecimiento tales como China e India puedan satisfacer la demanda futura de alimento humano y animal y de biocombustibles sin agravar substancialmente los problemas ya existentes de escasez de agua". Según la entidad ecologista GRAIN (www.grain.org/front/), casi toda la caña-de-azúcar de la India -el principal cultivo para producción de etanol del país- es de irrigación, así como aproximadamente un $45 \%$ del principal cultivo para agro combustibles de China, el maíz. El pronóstico es que en la India y en China, países donde el agua ya está siendo peligrosamente agotada o contaminada, para el año 2030 aumentarán su demanda de agua para irrigación en $13 \%$ o 14\%, solamente para mantener la producción de alimentos en los niveles actuales. Si esos países optaran por los agro combustibles en gran escala esos cultivos consumirán mucho más de la ya escasa agua para irrigación.

El análisis del discurso de diferentes ideólogos conectados a los agro negociantes, como Roberto Rodrigues y varios investigadores de la EMBRAPA, de la USP y del ICONE, no deja de resaltar el lugar que atribuyen a Asia como el gran mercado buscado. El mapa deja eso claro, incluso porque esos ideólogos identifican los Estados Unidos como un mercado pasajero, en vista de las condiciones tanto de tierra como de agua, además del dominio tecnológico que pueden garantizar a los Estados Unidos su abastecimiento de energía. $^{41}$ Toda el problema es cómo los Estados Unidos resolverán internamente la ecuación alimento-energía, conforme su estrategia geopolítica que, hasta hoy, se sostuvo en, de un lado, seguridad alimentaria y de minerales y, del otro, acciones imperialistas. Frente a eso, el megaproyecto IIRSA es estratégico para ese complejo de poder, por ofrecer la logística necesaria para la integración con el Pacífico, particularmente anhelada por los agro negociantes brasileños.

Según Thomas Shannon, subsecretario adjunto de Estado de los Estados Unidos para el Hemisferio Occidental, ya en el segundo semestre de 2007 comenzará la cooperación efectiva entre Brasil y Estados Unidos para la instalación de una cadena productiva de

\footnotetext{
${ }^{41}$ El mapa revela, además, que Australia dispone de mucha tierra, pero de poca agua. África, aunque dispone de grandes extensiones de tierra en gran parte desérticas, como en el norte, en el Sahara, y al sur, en el Kalahari, posee en su zona ecuatorial (Zaire, Congo, Gabón) gran disponibilidad de agua y tierras. En Europa, a su vez, con excepción de Francia, la disponibilidad de tierras y de agua está abajo de la media mundial.
} 
etanol en Haití, en El Salvador, en Saint Kitts and Nevis y en Costa Rica, con el apoyo del Banco Interamericano de Desarrollo (BID), según el reportaje "Diplomacia del etanol aproxima a Brasil y Estados Unidos" de Denise Marin, publicada en el Cuaderno Economía \& Negocios de $O$ Estado de São Paulo en 15 de julio de 2007.

De acuerdo a otro reportaje, "Biocombustibles es el foco del viaje de Lula a América Central", publicada en el periódico Folha de São Paulo en 6 de agosto de 2007, el presidente Lula inició un viaje acompañado de cincuenta empresarios, y ningún líder comunitario o sindical, a México y otros cuatro países (Nicaragua, Honduras, Panamá y Jamaica), teniendo en la agenda, sobre todo, el programa de energía de biomasa. Para México, que ya sufre los efectos de la política de producción de agro combustibles, el etanol a partir del maíz y que le dio origen a la crisis "de las tortillas", Lula le ofrece la tecnología de explotación de petróleo en aguas profundas, ${ }^{42}$ en la cual la Petrobrás detenta el liderazgo en todo el mundo. Para los demás países, la aproximación del Brasil hace posible aprovechar los TLCs, por intermedio de los cuales se podrá exportar hacia los Estados Unidos sin las barreras que les son impuestas. Ese reportaje habla explícitamente del ALBA, referencia rara en los grandes mass media brasileño, lo cual es un fuerte indicio del sentido geopolítico ocasionado en esa aproximación entre Estados Unidos y Brasil.

Existe una dificultad en el destino que pueda adoptar el IIRSA, debido a la posición estratégica de Bolivia y a las posiciones del gobierno de Evo Morales ${ }^{43}$ y del gobierno de Rafael Correa en el Ecuador, además del papel que viene desempeñando el gobierno de Chávez, no sólo en la financiación de proyectos de integración con características bolivarianas, sino también por las cláusulas sociales que viene defendiendo en los procesos de integración continental. Esos ejes de integración del IIRSA pueden constituir una nueva vena abierta de América Latina, de devastación y sufrimiento, ${ }^{44}$ como la Transamazónica y otras, o una oportunidad sin igual para un proyecto de reforma agraria de nuevo tipo, involucrando la integración de esos pueblos y culturas, con sus tradiciones técnicoculturales y estableciendo un diálogo con la tradición técnico científica europea, para afirmarse.

\footnotetext{
${ }^{42}$ Según el mismo reportaje, México tendría reservas del orden de 29 billones de barriles de petróleo en aguas profundas en la región del Golfo.

${ }^{43}$ No se debe olvidar que la elección de Evo Morales se siguió a las derrotas sucesivas experimentadas por el movimiento popular, particularmente por el movimiento indígena, que impuso la reapropiación nacional de sus recursos naturales (agua y gas, en especial), además de la renuncia de sucesivos gobiernos neoliberales.

${ }^{44}$ Buena parte de los grandes agro negociantes que operan en Brasil ve en el IIRSA la posibilidad de integración con Asia, según ello el gran mercado buscado para el etanol y el biodiesel.
} 


\section{La perspectiva subalterna}

América Latina tiene otros triunfos para el debate en torno a la transición energética, además de lo que viene siendo propuesto por los agro negociantes y su complejo técnico científico-agroindustrial-financiero-mediático, que ha destacado la disponibilidad de agua y tierras entre los triunfos fundamentales para tener en cuenta. El mapa "Agua y tierras disponibles por país" es esclarecedor del lugar central de América Latina, sobre todo de Brasil, en la nueva geografía política de la energía, aunque silencie otras cualidades de ese mismo espacio geográfico, conforme veremos.

En ese mapa, América, tanto al norte como al sur, está representada como disponiendo de gran disponibilidad de agua y tierras, aunque con distribución desigual, conforme lo muestra la situación de Chile, de Ecuador y de Perú, no obstante en los dos últimos casos haya gran disponibilidad de agua en su porción amazónica.

Hay que destacar, sin embargo, una cualidad de los países tropicales que es la mayor exposición a la insolación, lo que se traduce en una calidad excepcional cuando lo que está en juego es la producción de biomasa (fotosíntesis). Esa es una diferencia fundamental entre Estados Unidos y Canadá, por un lado, y América Latina y el Caribe, por el otro. Por último, la tropicalidad se presenta, hoy, con enorme potencial productivo, sobre todo cuando se persigue partir de sus cualidades naturales (fotosíntesis y agua), lo que, hasta aquí, era negado por una visión eurocéntrica que hablaba más de tristes "trópicos" en vez de hacer a la creatividad humana dialogar con las condiciones naturales. ${ }^{45}$

Esas dos cualidades de la tropicalidad (fotosíntesis + agua = biomasa en abundancia) están indisolublemente conectadas a una tercera, absolutamente silenciada en la visión de los agro negociantes, conforme el mapa en consideración: la diversidad biológica. Frente a todo el esfuerzo que ese complejo de poder en torno a los agro combustibles viene desarrollando para revestirse de ecológico, inclusive con toda la retórica en que prefijos como "bio" y "eco", además del término "verde", son antepuestos o pospuestos "biocombustibles", "combustibles verdes", "ecodiesel", "bio refinerías", para no citar biotecnología y biomasa- es muy extraño que no se hable de biodiversidad, cualidad que tiene en las regiones tropicales su mayor expresión (matas tropicales, ${ }^{46}$ sabanas, cerrados en Brasil $^{47}$ y llanos en Venezuela), además de las áreas inundadas del Darién (Colombia-

\footnotetext{
${ }^{45}$ Se evidencia aquí uno de los principales males del eurocentrismo, más preocupado de transferir su tecnología fundada en un saber que, según cree, es el único universal posible. Para una crítica, ver Lander (2006).

${ }^{46}$ Debemos destacar la selva Lacandona, en México, los bosques tropicales del Petén, en Guatemala, además de los bosques tropicales de los contrafuertes andino-amazónicos y del Pacífico, sobretodo el Sur Pacífico colombiano, y la mata atlántica brasileña.

${ }^{47}$ En Brasil, los cerrados y sus áreas de transición ocupan cerca de 300 millones de hectáreas y son los más afectados, desde fines de los años 1970, por la expansión de los monocultivos de los latifundios empresariales moderno-colonial de los agro negociantes de soja, maíz, algodón, girasol y ahora, cada vez más, de caña, sobretodo para exportación.
} 
Panamá), del Pantanal mato-grossense y de las extensas llanuras del Río Araguaia (en ese caso, con cerca de 2 millones de hectáreas).

Esas regiones disponen no sólo de inmensa riqueza en diversidad biológica, como también de un enorme patrimonio cultural expresado en una enorme variedad de pueblos que resis(exis)tieron tanto a la primera como a la segunda moderno-colonialidad, ${ }^{48}$ viviendo mucho más de su creatividad en el aprovechamiento de la enorme productividad biológica primaria -la biomasa- que de tecnologías que dependen de la importación de energía y fertilizantes, como la tradición europea con sus "revoluciones verdes" capitaneadas por los agronegociantes de ayer y de hoy. Además de que esas áreas albergan topoi de diversos pueblos originarios de América (Abya Yala, según la denominación propia de ellos), como los mayas, los cunas, los ashar, los misquitos, los guaraníes, los tupiniquins y los aimarás, hay, además, diversas expresiones de campesinidad, como el indigenato $^{49}$ de que habló Darci Ribeiro, así como poblaciones que se volvieron a crear bajo el refugio de esa naturaleza pródiga, como los ribeirinhos de Amazonia, los retireiros del Araguaia, los afro-descendientes en sus palenques, quilombos y cumbes, sea en Venezuela, en Colombia o en el Panamá. El acervo de conocimiento proveniente de esos pueblos bajo la forma de alimentos y remedios de los que la humanidad dispone es enorme, comenzando con el maíz, la mandioca y la patata, para no hablar del tabaco, la goma, la coca, la quinina y tantas otras invenciones culturales.

Esas poblaciones ocupan los hábitats que, hoy, las grandes empresas del monocultivo ven como gran disponibilidad de agua y tierras, para expandir sus negocios. Por eso hablan de agro negocio y no de agricultura, y con eso dejan fuera una de las principales cualidades de la vida biológica, en el caso de la especie humana, cual es la de crear sentidos para la vida, de inventar culturas. De ahí, el "olvido" de la cultura, o sea, de esa otra cualidad de la vida, en el mapa geopolítico que ese bloque de poder hegemónico busca forjar. Esas poblaciones se revisten, exactamente por eso, de enorme valor estratégico y deben, definitivamente, colocarse como protagonistas de una nueva geopolítica pensada y actuada

\footnotetext{
${ }^{48}$ La primera moderno-colonialidad estuvo bajo hegemonía ibérica, desde fines del siglo XV a los inicios del XIX. La segunda moderno-colonialidad estuvo bajo la hegemonía de los países de la Europa norte-ocidental y, en el siglo XX, de los Estados Unidos, principalmente. Ver Porto-Gonçalves (2006).

49 "Indigenato", según Darci Ribeiro, eran los campesinos étnicamente diferenciados, término que se refería a las grandes masas de poblaciones de Perú, de Ecuador, de Bolívia, del sur de Chile, de Guatemala y del sur de México, sobretodo. La sociología latino-americana, liberándose cada día más de la colonialidad del saber eurocéntrico, debería rescatar esa categoria legada por Darci Ribeiro. Además, la pista conceptual de ese autor puede ser extendida al campesinado de modo general, en la medida en que el saber local, culturalmente diferenciado, es una de sus principales características.
} 
a partir de la subalternidad. ${ }^{50}$

Aquí hay una lucha, al mismo tiempo, epistémica y política, y encuentros posibles de epistemes que fueron subalternizadas en Europa, como la de los fisiócratas y de los campesinos, y las matrices latinoamericanas y caribeñas, sea de los pueblos originarios, sea de las campesinidades ya señaladas. Como hay otras epistemes que aún habiendo surgido en el mundo de la subalternidad en Europa, como el marxismo, necesitan volver a pensar su eurocentrismo cuando vienen hacia el lado colonial del sistema-mundo moderno-colonial, donde la lucha contra el capital gana otros contornos, como lo demuestran las experiencias de las múltiples campesinidades y de los pueblos originarios que experimentan, como sufrimiento, la modernidad hace quinientos años y resis(exis)ten además que resisten (Porto-Gonçalves, 2002).

Sin embargo, hay un aprendizaje traído por esa tradición del pensamiento subalterno europeo, el marxismo, que ayuda a comprender gran parte de lo que está en curso y la tragedia que se anuncia con la expropiación generalizada que advendrá de la expansión de esos latifundios del monocultivo moderno-coloniales de los agro negociantes, sobre todo cuando quieren someter la producción agrícola a la producción de combustibles de biomasa. Se trata de la comprensión del carácter, desde siempre, mundial del capitalismo y del papel del desarrollo de las fuerzas productivas que el capital impone al mundo. Si superáramos la visión que sitúa las fuerzas productivas de un lado y las relaciones de producción de otro, como hace cierto estructural-funcionalismo marxista, veremos que el desarrollo de las fuerzas productivas no es externo a las relaciones sociales y de poder (Porto-Gonçalves, 2006). Se torna claro que estamos asistiendo a una profunda transformación en las relaciones sociales y de poder por medio de la tecnología, de ahí el concepto inspirado en Pablo González Casanova (2006) de complejo técnico-científicoagroindustrial-financiero-mediático que estamos proponiendo. Es desde una dialéctica compleja que necesitamos pensar un capitalismo complejo, como vienen insistiendo Pablo González Casanova, Enrique Leff (2006), Arturo Escobar (1996), Héctor Díaz-Polanco, Pablo Dávalos (2005) y Boaventura de Sousa Santos (2004), por un lado, y el Movimiento Pachakutik, en Ecuador y en Bolivia, la Confederación de Nacionalidades Indígenas del Ecuador (CONAIE), el movimiento zapatista, en México, el indigenato guatemalteco, los mapuches en Chile, los afro-descendientes del Pacífico Sur colombiano, el Movimiento de los Trabajadores Rurales Sin Tierra (MST) y varias entidades campesinas en Brasil, como

\footnotetext{
${ }^{50}$ Por más que la tradición hegemónica europea, con su antropocentrismo, haya afirmado el papel de la dominación de la naturaleza, allá mismo en Europa hay otras tradiciones, entre ellas la fisiocracia, que abren la posibilidad de una hermeneútica diatópica (Boaventura de Sousa Santos), de una ética de la otredad (Lévinas), que bien pueden aproximarse a la racionalidad ambiental, de Enrique Leff, y de un diálogo entre matrices de racionalidad diferentes (Leff y Porto-Gonçalves) o de una coexistência entre civilizaciones, como propone Simon Yampara y otros a partir del mundo andino amazónico.
} 
los quilombolas. Una dialéctica que sabe que la totalidad del mundo no está compuesta solamente por la relación capital-trabajo, sino también por otras tensiones mediante las cuales múltiples sujetos vienen constituyéndose en la relación con/contra el capital.

Es a partir de ese análisis que, creemos, es posible visualizar los desafíos que se presentan, al comenzar por afirmar el capital simbólico y político adquirido en las luchas locales por esos diferentes sujetos. En un mundo en que los ideólogos hegemónicos, por medio de los grandes mass media, no se cansaron de afirmar el carácter homogeneizador de la globalización, venimos a afirmar el derecho a la diferencia, hasta tal punto que esos mismos protagonistas hegemónicos se ven obligados a considerarla y a intentar instrumentalizarla, folclorizándola o aislándola-divide et impera.

Hoy, sin embargo, con la unión entre el capital agrario y el industrial, el financiero, el de las grandes empresas de mass media y el mundo técnico-científico, de organización en red, está en curso el proceso de expropiación no sólo de los recursos naturales ${ }^{51}$ sino, principalmente, de los conocimientos de los campesinados y de los pueblos originarios, lo que implica, una vez más, desterritorializarlos, ahora por la des-localización del locus de producción de conocimiento en la relación directa con la naturaleza por y para una relación mediatizada por los laboratorios, cada vez más empresariales - finalmente, al retirar del lugar, o mejor, retirar de los hombres y de las mujeres del lugar el poder de reproducirse por medio de los propios conocimientos. No olvidemos que cada semilla contiene no sólo el germen del alimento, sino además conocimiento -en ese caso, información genética culturalmente elaborada. Hoy, la posibilidad de existencia de esos grupos está directamente vinculada a su capacidad de desarrollar una lucha política en el núcleo del locus de bifurcación tecnológica, ${ }^{52}$ pasando a constituir el atractor de un sistema emergente

\footnotetext{
${ }^{51}$ El capital parece convencerse de que no consigue vivir sin ellos, si es que algún día creyó verdaderamente en su ideología antropocéntrica, también porque nunca dejó de enviar tropas y establecer bases militares para garantizar la dominación del hombre sobre la naturaleza, incluso sobre la naturaleza diversa de otros hombres y mujeres.

${ }_{52}$ Algunos ejemplos fundamentales de la lucha política en ese campo que cada vez más debe hacer parte de la agenda política de los movimientos sociales: (1) la definición físico-química de los motores va a especificar las especies de plantas más aptas para su producción, lo que va a ser determinante para la vida de las poblaciones que las dominen o no, o tengan sus territorios propicios o no para su producción; (2) la necesidad de incorporar, de modo central y no marginal o retórico, como hoy, otras fuentes renovables (geotermia, energía eólica, energía mareomotriz) a la matriz energética, ya que la biomasa es solamente una de las fuentes a ser consideradas; (3) la búsqueda de motores movidos por eletricidad, sobretodo por baterías; (4) la racionalización en el consumo y en la distribución de energía, evitando el distanciamiento entre los lugares de producción y los lugares de consumo de energía, donde hay un gran desperdicio de potencia. Todo indica que la solución del problema no pasa por el lado de la oferta de combustibles, sino, principalmente, por el lado de la demanda, en que se impone no solamente una revolución cultural, como también la búsqueda de alternativas a los motores Otto y Diesel. Definitivamente, la lucha política tendrá que hacerse en el campo de la lucha del conocimiento, en sus aplicaciones y sus implicaciones.
} 
(Prigogine) que tenga en la productividad biológica primaria, en la justicia social y en la diversidad cultural los soportes de una racionalidad ambiental (Leff, 2006) - en resumen, de proponer una nueva lógica a la técnica, de afirmar otra (tecno)lógica que no abdique de una ética y de una moral expresada políticamente por nuevas $\mathrm{y}$, principalmente, otras prácticas.

La reforma agraria adquiere, así, un sentido completamente nuevo, en la medida en que implica una profunda revolución cultural, una nueva relación de las sociedades con la naturaleza, una nueva relación entre y con los lugares, una racionalidad ambiental en que se abra un diálogo entre matrices de racionalidad distinguidas, en que no haya tanto desperdicio de experiencias como aquel engendrado por la colonialidad del saber y del poder (Sousa Santos). Si de lo trata es de dar un nuevo sentido a la relación con la naturaleza cuando se habla de reforma agraria, ya no es simplemente más de tierra de lo que estamos hablando, sino de territorios y sus múltiples territorialidades. Aquí, el diálogo entre los diferentes tiene que integrarse con la materialidad de la naturaleza y de los lugares, ese olvido que la tradición occidental llevó más lejos que cualquiera otra civilización y que, hoy, nos obliga a debatir otro sentido a ser dado al trabajo y a la energía, bajo la amenaza de la expresión material de ese propio olvido: el calentamiento global. 


\section{Bibliografía}

Amin, Samir (2003), O capitalismo e a nova questão agrária, Fórum do Terceiro Mundo, Senegal.

Disponible en: <http://resistir.info/samir/pobreza_mundial.html>. Acceso en: 3 nov. 2003.

González Casanova, Pablo (2006), As novas ciências e as humanidades: da academia à política, Boitempo, Rio de Janeiro.

GRAIN (2007), iNo a la fiebre de los agrocombustibles! 28 jun. 2007. Disponible en: <www.grain.org/nfg/?id=504>.

Holt-Giménez, Eric. (2007), Os cinco mitos da transição dos agrocombustíveis. Disponible en:<www.adital.com.br/site/noticia.asp?lang=PT\&cod=28506>. Acceso en: 3 ago. 2007.

Koplow, Doug (2006), Biofuels: at what cost? Government support for ethanol and biodiesel in the United States, GSI. Disponible en: 〈http://tinyurl.com/2s5mpw〉. Acceso en: 4 jul. 2007.

Lander, Edgardo (2006), A colonialidade do saber: eurocentrismo e ciências sociais, CLACSO, São Paulo/Buenos Aires.

Leff, Enrique (2006), Racionalidade ambiental, Civilização Brasileira, Rio de Janeiro.

Mari, Eduardo (2000), El ciclo de la tierra: minerales, material reciclado, contaminación ambiental, Fondo de Cultura Económica, Buenos Aires.

Marx, Karl (1974), Crítica dos programas socialistas de Gotha e de Erfurt, Tip. Nunes, Porto. (Orig. 1875.)

Porto-Gonçalves, Carlos Walter (1983), Os limites de "os limites do crescimento”, Dissertação (mestrado) Departamento de Geografia, UFRJ.

Idem (2002), "Latifúndios genéticos y existência indígena" en Revista Chiapas, México, № 14, pp. 7-30.

Idem (2006), A globalização da natureza e a natureza da globalização, Civilização Brasileira, Rio de Janeiro.

Tokar, Brian (2006), Running on hype: counterpunch, nov. 2006. Disponible en: 〈http://tinyurl.com/w5swf . 